\title{
Utilization of the seven principles for good practice in undergraduate education in general chemistry by community college instructors
}

Jennifer Panther Bishoff

West Virginia University

Follow this and additional works at: https://researchrepository.wvu.edu/etd

\section{Recommended Citation}

Panther Bishoff, Jennifer, "Utilization of the seven principles for good practice in undergraduate education in general chemistry by community college instructors" (2010). Graduate Theses, Dissertations, and Problem Reports. 2955.

https://researchrepository.wvu.edu/etd/2955

This Dissertation is protected by copyright and/or related rights. It has been brought to you by the The Research Repository @WVU with permission from the rights-holder(s). You are free to use this Dissertation in any way that is permitted by the copyright and related rights legislation that applies to your use. For other uses you must obtain permission from the rights-holder(s) directly, unless additional rights are indicated by a Creative Commons license in the record and/ or on the work itself. This Dissertation has been accepted for inclusion in WVU Graduate Theses, Dissertations, and Problem Reports collection by an authorized administrator of The Research Repository @ WVU.

For more information, please contact researchrepository@mail.wvu.edu. 
Utilization of the Seven Principles for Good Practice in Undergraduate Education in General Chemistry by Community College Instructors

\author{
Jennifer Panther Bishoff
}

Dissertation submitted to the College of Human Resources and Education at West Virginia University in partial fulfillment of the requirements for the degree of

\title{
Doctor of Education
}

in

Educational Leadership Studies

Elizabeth Jones, Ph.D., Chair

Ernest Goeres, Ph.D.

Jason Johnson, Ph.D.

Richard Walls, Ph.D.

Michelle Richards-Babb, Ph.D.

Department of Educational Leadership

Morgantown, West Virginia 


\begin{abstract}
Utilization of the Seven Principles for Good Practice in Undergraduate Education in General Chemistry by Community College Instructors
\end{abstract}

Jennifer L. Panther Bishoff

In recent years, higher education has undergone many changes. The advent of assessment, accountability, and a newfound focus on teaching have required faculty to examine how they are teaching. Administrators and faculty are beginning to recognize that learning is not a "one size fits all" enterprise. To this end, Chickering and Gamson developed an inventory that examined faculty utilization of the Seven Principles of Good Practice in Undergraduate Education. The seven principles included by the authors included faculty-student interaction, cooperative learning, active learning, giving prompt feedback, emphasizing time on task, communicating high expectations, and respecting diverse talents and ways of learning. It was determined by Chickering and Gamson, as well as many other researchers, that these seven principles were hallmarks of successful undergraduate education.

Community colleges are important institutions to study, as many students begin their higher education at two-year colleges. Most students are also required to take one or more science classes for their general education requirements; therefore, many students must take at least one general chemistry course. Both community colleges and chemistry are rarely studied in literature, which makes this study important.

Community college general chemistry instructors were surveyed using an online version of Chickering and Gamson's Faculty Inventory for the Seven Principles of Good Practice in Undergraduate Education. Responses were analyzed, and it was discovered that not only did instructors utilize the principles to a different extent, but there were also differences between genders as well as between the specific actions related to each principle. 


\section{ACKNOWLEDGEMENTS}

This research could not have been completed without the support of those around me. I would like to acknowledge my family, including my husband, Josh, my children, Sophia and Lauryn, as well as my parents, Tom and Darla Panther. Without these people, none of this work would be accomplished.

I have also relied on the support and guidance of my advisor, Dr. Elizabeth Jones, who has patiently helped me every step of the way. My committee members have also offered so much assistance and encouragement along the way; Dr. Ernest Goeres, Dr. Jason Johnson, Dr. Michelle Richards-Babb, and Dr. Richard Walls have provided much feedback and support. I sincerely appreciate all of you, and without you, this would not have been possible. 


\section{TABLE OF CONTENTS}

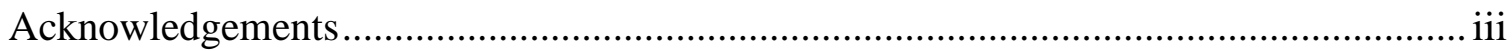

Table of Tables ............................................................................................... vi

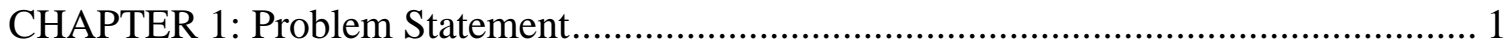

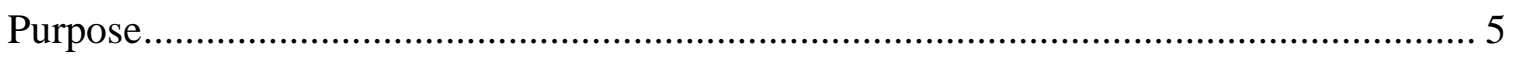

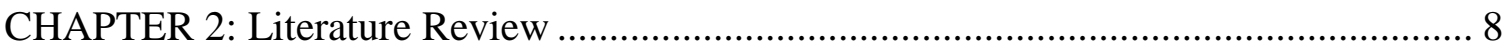

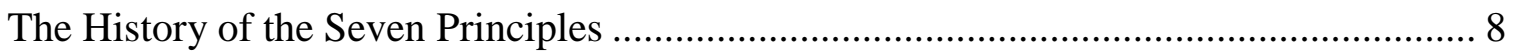

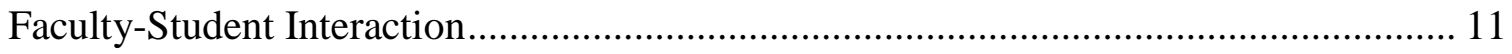

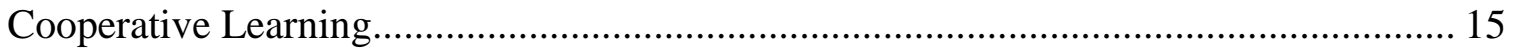

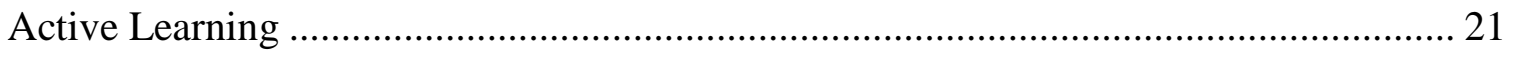

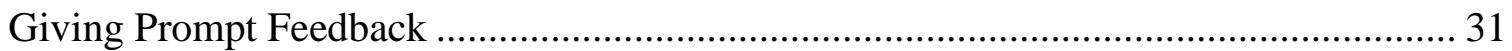

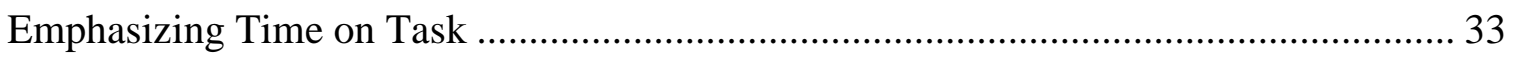

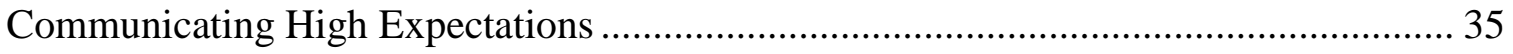

Respecting Diverse Talents and Ways of Learning ................................................. 39

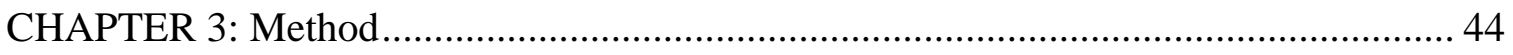

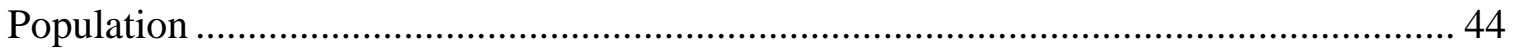

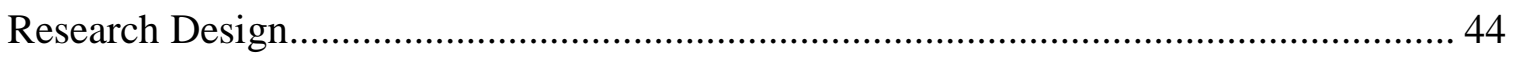

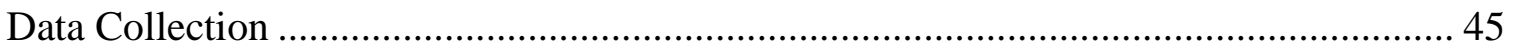

Utilization of Survey Data to Answer Research Questions ...................................... 45

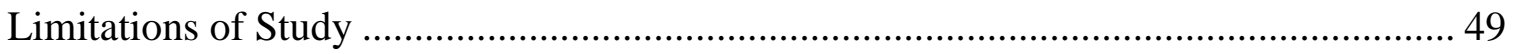

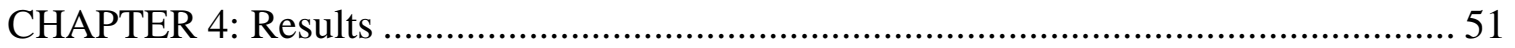

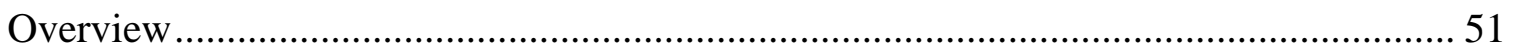

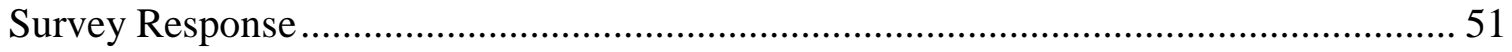




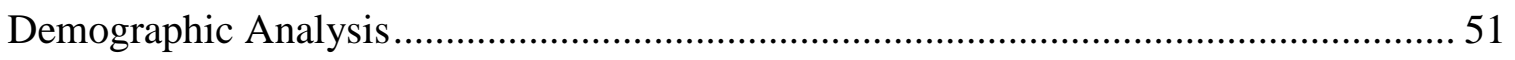

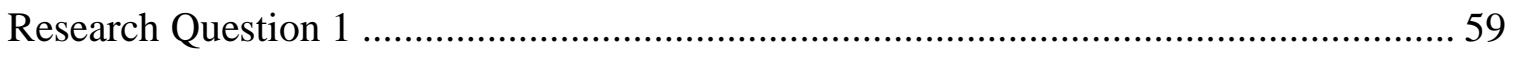

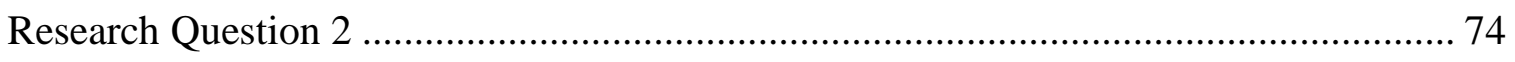

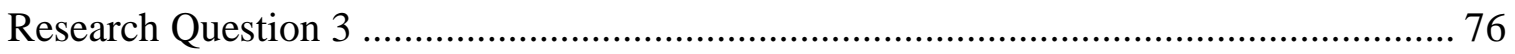

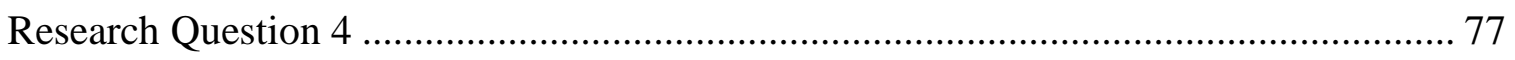

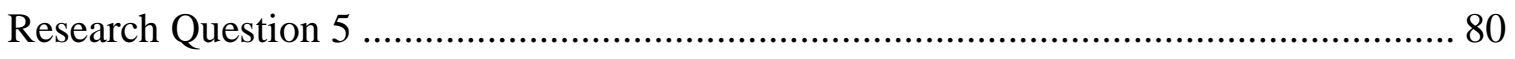

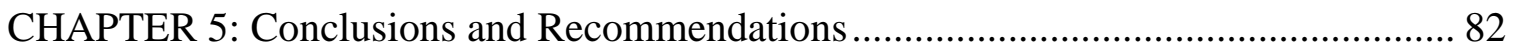

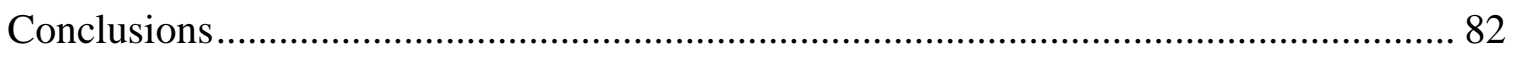

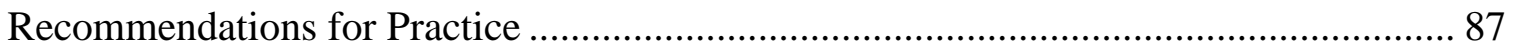

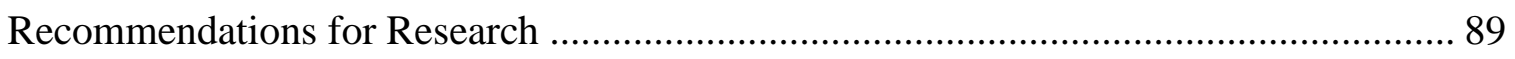

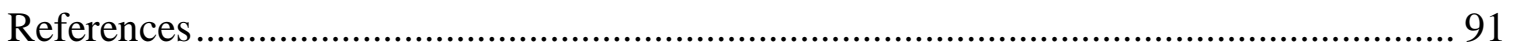

APPENDIX A: Faculty Inventory of the Seven Principles of Good Practice in

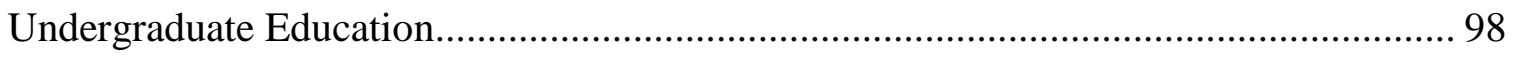

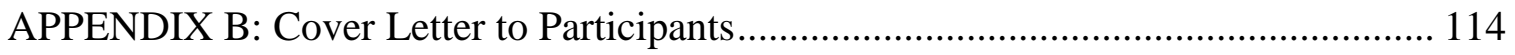

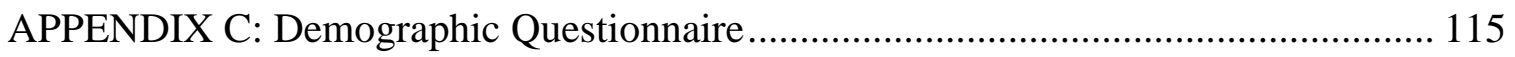




\section{TABLE OF TABLES}

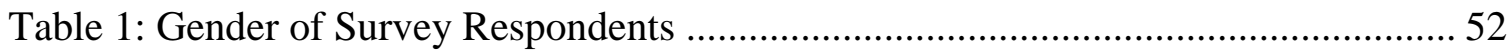

Table 2: Employment Status of Participants........................................................... 53

Table 3: Typical Chemistry Class Size of Participants................................................ 54

Table 4: Number of Years Teaching in Higher Education ......................................... 55

Table 5: Highest Degree Completed by Respondents ............................................. 56

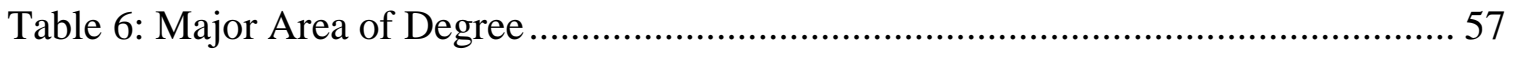

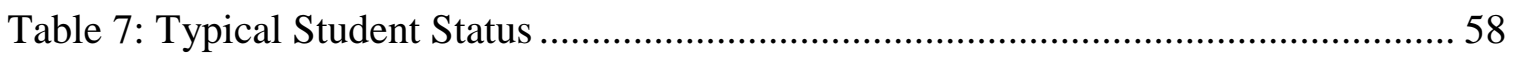

Table 8: Regional Accreditation Associated with Institutions .................................... 59

Table 9: Principle 1: Good Practice Encourages Student-Faculty Contact ..................... 61

Table 10: Principle 2: Good Practice Encourages Cooperation Among Students............ 63

Table 11: Principle 3: Good Practice Encourages Active Learning ............................... 65

Table 12: Principle 4: Good Practice Gives Prompt Feedback..................................... 67

Table 13: Principle 5: Good Practice Emphasizes Time on Task.................................. 69

Table 14: Principle 6: Good Practice Communicates High Expectations ....................... 71

Table 15: Principle 7: Good Practice Respects Diverse Talents and Ways of Learning.. 73

Table 16: Comparison of Principle Utilization by Type of Principles .......................... 75

Table 17: Principle Utilization by Accreditation Region .......................................... 77

Table 18: Comparison of Utilization of Principles by Gender .................................. 79

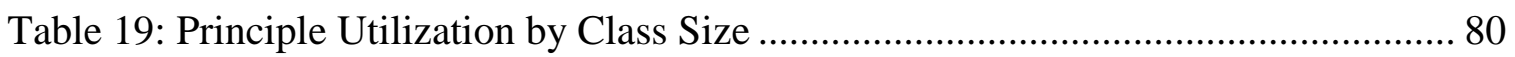




\section{CHAPTER 1}

\section{Problem Statement}

In recent years, higher education has undergone many changes. The advent of assessment, accountability, and a newfound focus on teaching have required faculty to examine how they are teaching. Administrators and faculty are beginning to recognize that learning is not a "one size fits all" enterprise. According to Barr and Tagg (1995), American higher education is undergoing a paradigm shift: the focus of colleges and universities is shifting from teaching to learning. No longer may colleges exist simply to provide instruction; “a college's purpose is not to transfer knowledge but to create environments and experiences that bring students to discover and construct knowledge for themselves" (Barr \& Tagg, 1995, p. 16). Chickering and Gamson recognized this in 1987 when they developed the Seven Principles for Good Practice in Undergraduate Education. Undergraduate education faculty must encourage student-faculty contact, encourage cooperation among students, encourage active learning, give prompt feedback, emphasize time on task, communicate high expectations, and respect diverse talents and ways of learning (Gamson, 1991).

The extent of student-faculty contact has been proven to be very important in many studies. Survey research by Volkwein and Cabrera (1998) concluded that undergraduates perceived their classroom experiences to be beneficial if there were high levels of faculty concern and interaction. Other studies have confirmed this finding, including Umbach and Porter (2002), who reported that higher incidences of student contact with faculty increase the perceived impact of college on skill development. The 
authors also state "when contact with faculty decreased (or average class size increased), average student ratings decreased" (p. 226).

Cooperation among students, or group learning, is another principle that has been the topic of many papers and books. Group work is vital in the classroom and can help students to solve open-ended problems more easily with input from other students (Reid \& Yang, 2002). Group work is especially problematic in chemistry, since "there is a genuine absence of transactions involving 'higher level' cognitive thinking... at least some of the educational benefits that are frequently claimed for group work in science are not realized" (Kempa \& Ayoub, 1991, p. 353). This suggests that more research must be done on how to effectively utilize group work in chemistry courses, as many other disciplines have found it useful (such as social studies, humanities, foreign languages, and mathematics) (Kadel \& Keehner, 1994).

Active learning implies a level of involvement by students that is typically not seen in traditional lecture, but is not limited to class discussion or laboratory work. "Students in an active learning classroom showed significant improvement in performance relative to students in a lecture-based course" (p. 448) in a four-semester study at the Naval Academy (O’Sullivan \& Copper, 2003). Active learning is typically underutilized in chemistry classrooms for various reasons. First of all, an active curriculum cannot simply be created and passed down; the faculty members using it must embrace it. According to Penberthy and Millar (2002), faculty must have personal convictions and motivation to teach this way in order for it to be an effective mode of teaching. Faculty are concerned that less material is covered in an active learning environment (O’Sullivan \& Copper, 2003). Zoller (1999) reported that "highly 
demanding teaching pedagogies, difficulty in translating higher-order cognitive skills teaching aims into specific learning objectives, unavoidable challenges to current conceptualization of science teaching, and structural conditions in which one is teaching" make it hard to implement active learning strategies (p. 593).

Prompt feedback is an important issue not only according to the Seven Principles, but also in assessment literature. According to Huba and Freed (2000), students must have feedback in order to improve in what faculty are trying to teach. "Learners...need to know what constitutes good performance, not just in their courses, but in the adult and professional world" (Huba \& Freed, 2000, p. 155). Huba and Freed (2000) also stressed promptness in feedback, stating "we should schedule feedback discussions in a timely manner, during as well as after assessment" (p. 193). Sorcinelli (1991) asserted that according to literature, "the most significant conclusion to be reached from research on innovative teaching methods, then, is that immediate, corrective, and supportive feedback is central to learning" (p. 15).

Time on task, or engaged time, has been studied extensively in elementary and secondary education. Many of the studies may be applied to higher education. For example, Metzker (2003) stated that in order to make time more productive in the classroom, the curriculum should be narrowed, clear goals and expectations should be established, and time should be allowed for contemplation and review. A literature review on curriculum time claimed "learning time is a major determinant of the amount of content comprehended" (Myers, 1990, p.3). Bracey (2001) asserted that students who receive good grades are more engaged than those with poor grades, and that at-risk students are less engaged than students who are not at risk. It is therefore vital that 
classroom time be managed appropriately to provide maximum learning opportunity for students.

The Wingspread Group (1993) stated that on many of the nation's campuses, expectations are too low: "Institutions that start with learning will set higher expectations for all students, then do a much more effective job of helping them to meet those expectations" (p. 13). High expectations are gaining more attention as the assessment movement progresses. Assessment requires stating goals and objectives at the outset of academic endeavors in order to measure whether or not goals have been reached at the end of the semester, unit, or other measure of time. Expectations should be stated at the beginning of the freshman year and re-stated in following semesters in order to reinforce ideals (Maitland Schilling \& Schilling, 1999). Many students' expectations of college "have been shaped by their experiences in high school, where demands for time were likely modest" (Maitland Schilling \& Schilling, 1999, p. 5). College studies are decidedly more time-consuming and rigorous, and many institutions are not clearly stating the "knowledge, skills, and capacities students are to attain" (Maitland Schilling \& Schilling, 1999, p. 5).

Students learn by different learning styles and methods. "Learning styles refer to the way students concentrate on, process, internalize, and recall new and difficult information" (Rochford, 2003, p. 665). It is important that higher education respect the differences in learning styles of undergraduates. Milshtein (2003) grouped learning styles in three broad categories: auditory, tactile, and visual. She stated that these learning styles are preferred due to "individual brain wiring and the way we absorb and store information” (Milshtein, 2003, p. 30). According to Rochford (2003), when 
students are taught according to their preferred style, they demonstrate significantly more recall than when they are taught through a less preferred style.

There is very little research on community college chemistry courses and the degree to which instructors utilize the Seven Principles of Good Practice in Undergraduate Education. With the increasing number of traditional and non-traditional students choosing community colleges for introductory course work, it is vital that an examination be done on how general chemistry is taught.

\section{Purpose}

The purpose of this study was to examine faculty utilization of specific good practices in general chemistry courses offered at community colleges. This was measured by Chickering and Gamson's (1991) Faculty Inventory of the Seven Principles of Good Practice in Undergraduate Education. The researcher collected demographic information, including class size and gender. Then, the extent to which each principle was utilized was measured according to responses of how often and how different modes of principle components are used. The results indicated which principles are used most frequently in general chemistry. The benefits and challenges of using the principles were investigated. Finally comparisons were made in the use of each principle by accreditation region, gender, and class size.

This study was a "state of the art" report, leading to an understanding of how frequently community colleges utilize Chickering and Gamson's Seven Priniples in their chemistry classrooms. This examination addressed a gap in the community college research base, in the chemistry education base of knowledge, and in the continuing research on the Seven Principles. This study also examined a course that is typically seen 
as a "gateway" course into further study. Gateway courses are important because they are usually the first courses college freshmen encounter and are often the courses that help them decide what their educational path will be. The results from this study provided information suggesting areas of improvement and strengths of undergraduate chemistry courses. Through this study, faculty and administration will learn about specific areas to address in faculty development in an effort to improve practice. This research could also be useful to faculty in other disciplines who seek to incorporate new teaching strategies in their classrooms.

The following research questions were explored in this study:

1. To what degree were community college chemistry faculty using Chickering and Gamson's (1991) Seven Principles of Good Practice in Undergraduate Education?
a. Encouraging faculty-student contact
b. Encouraging cooperation among students
c. Encouraging active learning
d. Giving prompt feedback
e. Emphasizing time on task
f. Communicating high expectations
g. Respecting diverse talents and ways of learning

2. Was there a significant difference in principle utilization by type of principle?
a. Faculty-student contact
b. Cooperation among students
c. Active learning 
d. Prompt feedback

e. Time on task

f. High expectations

g. Respect diverse talents and ways of learning

3. Was there a significant difference in utilization of principles by accreditation region?

a. The Middle States Association of Colleges and Schools

b. The New England Association of Schools and Colleges

c. The North Central Association of Colleges and Schools

d. The Southern Association of Colleges and Schools

4. Was there a significant difference in utilization of principles by gender of chemistry instructor?

5. Was there a significant difference in utilization of principles by class size (small, medium, large)?

This chapter outlined the problems and challenges found in community colleges, the purpose and significance of the study, and the research questions. Chapter 2 presents a review of scholarly literature regarding active learning and chemistry. Chapter 3 describes the research design that was utilized to answer the research questions. This chapter describes the sample, survey procedures, and analysis. The appendices include the cover letter and survey instruments that will be used in the study. 


\section{CHAPTER 2}

\section{Literature Review}

\section{The History of the Seven Principles}

Concern over the traditional lecture method of instruction was noted as early as 1961 by Bent, who delivered this criticism of the lecture: "For students who can read and for teachers who can write, a formal lecture is often an inconvenient, financially costly, and unreliable device for transferring information from a lecturer to a student” (p. 1). Bent's suggestion was to deliver course information by mimeograph, however, which is not the recommendation currently given for effective undergraduate education. Many current practitioners gain ideas and suggestions for effective teaching and learning strategies from the Seven Principles of Good Undergraduate Education, devised in 1987 by Arthur Chickering and Zelda Gamson. According to Gamson, the inspiration for the Seven Principles was a book by Theodore Sizer entitled Horace's Compromise (1991, p. 6). This book "lists nine principles that should guide teachers and administrators who want to improve their schools." Gamson's idea was to apply this to colleges and universities, and to provide an easy-to-read format for the lists of recommendations from reports. Many experts, such as Alexander Astin, K. Patricia Cross, and Jerry Gaff, met to generate the principles at Wingspread in 1986 (Gamson, 1991). They eventually decided that a list specifically for faculty members was not inclusive enough for their scope; instead, they wanted to include "campus administrators, state higher education agencies, and governmental policymakers" (Gamson, 1991, p. 7). The final version of the Seven Principles was presented in the March 1987 issue of the AAHE Bulletin and was greeted with an enthusiastic response from the higher education community. This response led 
Chickering and Gamson to develop a self-assessment instrument for faculty members and for institutions (Gamson, 1991). Final versions of the Faculty and Institutional Inventories were presented in 1989 by the Johnson Foundation in booklet form (Gamson, 1991). A student inventory was developed in 1990 (Chickering \& Ehrmann, 1996). Gamson states that the committee has learned "that the Inventories offer a good starting point for spirited conversations about teaching and the institutional environment for good teaching" (Gamson, 1991, p. 10). However, the Inventories are not designed as evaluation tools. This use of the Inventories is indicated on the documents as “illegitimate and psychometrically invalid” (Gamson, 1991, p. 10).

One hypothesis regarding successful implementation of the Seven Principles has been presented by Braxton, Olsen, and Simmons (1998). They contest that the Seven Principles are most successfully implemented in low paradigmatic disciplines such as history, psychology, and sociology; disciplines such as biology, chemistry, and physics are less likely to utilize the Seven Principles (Braxton, Olsen, \& Simmons, 1998). Recent utilizations of the Seven Principles in college-level courses include Management Science courses, Business Writing courses, and Geography courses. The Management Science and Business Writing courses at the University of West Florida are examples of courses that utilize the Seven Principles (Page \& Mukherjee, 2000). According to Page and Mukherjee (2000), Management Science is typically a course met with trepidation from students, and Business Writing is met with confidence. However, both courses utilize each of the Principles. For example, student-faculty contact was encouraged in Management Science by office hours and meetings with the professor. It was encouraged in Business Writing by telephone, fax, and e-mail communication along with office 
hours. Cooperation among students was fostered by group work in and out of the classroom, as well as in preparation for exams in the Management Science course. In the Business Writing course, cooperation was promoted by peer feedback on assignments. Active learning was supported in the Management Science course by the use of realworld problems; in Business Writing it was supported by student teaching of grammatical principles.

In Management Science, tests and assignments were graded by the next class period and deductions of points are justified by the instructor. This supported prompt feedback. In the Business Writing course, quizzes were graded "on the spot" by the instructor and papers were exchanged between peers to foster prompt feedback. Time on task, a principle vital to Management Sciences, was mastered by categorical teaching methods. For example, if a concept was deemed "very important," the concept was explained and three problems were solved during the class period. Students were then required to work a similar problem and submit for grading and possible resubmission. If a concept was only "to be covered," only one problem was solved in class. In Business Writing, classroom exercises, quizzes, and spelling bees were utilized to promote time on task. High expectations were communicated in Management Science in "a round about way" (Page \& Mukherjee, 2000). Expectations were set reasonably high (according to the group of students) and the instructor did whatever it took, including time and patience, to achieve these goals. Business Writing students were encouraged by four steps to success in the course. Finally, diverse talents and ways of learning were respected in Management Science by solving problems in different contexts and by different methods. In Business Writing, weaker students were given more personal time 
with the instructor. According to Page and Mukherjee (2000), implementing the Seven Principles led to decreased student apathy and increased student curiosity and involvement, as well as personal satisfaction for the instructor. Page and Mukherjee (2000) also noted barriers to the implementation of the Seven Principles, including course preparations, a "publish or perish" attitude, little or no rewards for teaching, and administrative responsibilities.

Ritter and Lemke (2000), instructors of Introductory Physical Geography at the University of Wisconsin, addressed the Seven Principles using the Internet and have reported success as determined by a student survey. They used six of the seven principles, omitting Cooperation Among Students, as they did not utilize collaborative learning. Student-faculty contact was encouraged by the use of e-mail and websites. Internet course materials, field trips, and modules fostered active learning. Feedback was promptly administered through e-mail and instant feedback on online exercises. Time on task was managed through effective use of time outside of the classroom by using Internet class materials. Course materials were also presented in a direct manner to prevent aimless surfing of the Internet. Questions for reflection, review and practice test questions, and guidelines on performance levels all contributed to communicating high expectations in Physical Geography. Finally, high-quality graphics, course outlines, laboratory exercises, modules, and virtual field trips helped students with diverse talents and ways of learning succeed.

\section{Faculty-Student Interaction}

Bent (1961) noted the importance of faculty-student interaction in his report, claiming "there are many ways to inspire students: getting to know them personally, in 
curricular and (importantly) extra-curricular activities; answering their questions, individually and before large classes; solving problems for them, unrehearsed, at the blackboard; preparing them for interesting and instructive lecture demonstrations" (p. 2). Literature indicates positive correlations between increased faculty contact and student performance and accountability. In his 1980 study, Pascarella examined 36 studies of educational outcomes and discovered a relevant link between the amount of studentfaculty contact and whether or not educational outcomes were reached. Increased faculty contact can also help to hold "students accountable for incidents of academic dishonesty and other inappropriate behaviors" (Maitland Schilling \& Schilling, 1999, p. 9). Other benefits of increasing faculty-student interaction include an early connection between faculty and student, faculty becoming role models, and more student participation in research (Teaching Tips, 2003). For example, "in the Undergraduate Research Opportunities Program at Massachusetts Institute of Technology, three out of four undergraduates join three-quarters of the faculty as junior research colleagues" as the result of increased interaction (Teaching Tips, 2003, p. 108). Light (2001) also noted “one-on-one working relationships between students and professors provide opportunities for students to take some responsibility for planning and running academic projects. These experiences teach students something they may not be able to learn in standard classes" (p. 108). Faculty-student interaction also increases student satisfaction with the college experience. Umbach and Porter (2002) studied how academic departments impact student satisfaction and noted that when contact with faculty decreased, so did the satisfaction ratings. The authors found that in departments where more research took place, such as chemistry and biology, student satisfaction was higher (Umbach \& Porter, 
2002). However, as Neumann and Finaly-Neumann point out in their 1989 study of alternative models of assessment in hard and soft sciences, students in hard sciences such as chemistry tend not to value faculty interaction as highly as those in soft sciences such as psychology.

In Teaching Tips: Using the 'Seven Principles of Good Undergraduate Education' to Increase Student Centered Learning, many recommendations for incorporating the principle regarding faculty-student interaction were discussed. For example, Brigham Young University encouraged faculty to do the following: host open office hours and encourage student visits, attend student-sponsored events, work with student affairs staff, and bring students to professional conferences or events (Teaching Tips, 2003). Northern Essex Community College (NECC) asked faculty to send introductory letters to advisees and students to welcome them before the semester and invite them to visit. NECC also encouraged personal interaction between faculty and students, suggesting that faculty "ask students how they are doing from time to time" and “treat students like human beings with full real lives" (Teaching Tips, 2003, p. 107). Asking student opinion, walking with students between classes, and arranging social orientations was also encouraged at NECC.

The current explosion in technology use can be effectively utilized to further faculty-student interaction. As stated in Teaching Tips (2003):

Traditionally, time-delayed communication took place in education through the exchange of homework, either in class or by mail (for more distant learners). Such time-delayed exchange was often a rather impoverished form of conversation, typically limited to three conversational turns: 
1. The instructor poses a question (a task).

2. The student responds (with homework).

3. The instructor responds some time later with comments and a grade.

The conversation often ends there. (Teaching Tips, 2003, p. 108).

According to Chickering and Ehrmann, such innovations as e-mail, discussion boards, and chat rooms have allowed students to communicate more openly and more often than in traditional lecture rooms (1996). According to their report, "with the new media, participation and contribution from diverse students become more equitable and widespread" (Chickering \& Ehrmann, 1996). Ritter and Lemke (2000) concurred with these findings, stating that e-mail "has increased contact with students." Teaching Tips adds to the discussion by expounding on how technology improves faculty-student interaction. For example, by allowing a "more 'distant' source of information and guidance for students, such technologies can strengthen faculty interactions with all students, but especially with shy students who are reluctant to ask questions or challenge the teacher directly" (Teaching Tips, 2003, p. 108). Students were often more likely to "open up" to faculty in writing, "since inadvertent or ambiguous nonverbal signals are not so dominant" (Teaching Tips, 2003, p. 108). Also, "as the number of commuting part-time students and adult learners increases, technologies provide opportunities for interaction not possible when students come to class and leave soon afterward to meet work or family responsibilities" (Teaching Tips, 2003, p. 108). E-mail and the Internet also allow students whose native language is not English to communicate more easily with faculty and staff (Teaching Tips, 2003). 
Barriers to increased student-faculty contact mentioned in literature include large class sizes and faculty workload. Barr and Tagg (1995) acknowledged the negative impact of increased class size and faculty workload, stating that "if a college attempts to increase its productivity by increasing either class sizes or faculty workloads, for example, academics will be quick to assume inexorable negative consequences for educational quality" (p. 2).

\section{Cooperative Learning}

Bent (1961) cited psychologists as stating "that the most effective way to inspire students - i.e. the most effective way to modify significantly their behavioral patterns - is through interpersonal relationships with their peers" (p. 2). He went on to suggest that the chemistry curriculum needs to incorporate and encourage group work, especially between beginning and more advanced students (Bent, 1961). Light asserted, "small groups appear to be even more important for the sciences than for courses in any other field" (2001, p. 74). Further, "substantive work in the sciences should be structured to involve more interaction with other students" (Light, 2001, p. 75). Light (2001) suggested doing this by forming small work groups to meet after lab experiments:

That way, rather than going home alone into the night, students can immediately share findings, frustrations, and surprises with others. They become part of a continuing conversation among young fellow scientists...small groups accomplish something else that students report is crucial—-they build collegial spirit, in a collegial community. And that is crucial for success in the sciences too. Students long for it. (p. 75-76). 
Johnson, Johnson, and Smith (2006) defined cooperative learning as "the instructional use of small groups so that students work together to maximize their own and each other's learning" (p. 1.12). Cooperative learning can be contrasted with competitive and individualistic learning generally seen in college classrooms. Johnson, Johnson, and Smith noted that "since the first research study was published in the late 1800 s, there have been over 600 experimental and over 100 correlational studies conducted on cooperative, competitive and individualistic efforts. The multiple outcomes studied can be classified into three major categories: efforts to achieve, positive relationships, and psychological health" (2006, p. 1:13). From the research, the authors have ascertained the following outcomes for cooperative learning, but not for competitive or individualistic learning:

1. Greater efforts to achieve

2. More positive relationships among students

3. Greater psychological health (Johnson, Johnson, \& Smith, 2006)

After describing the research and benefits of cooperative learning, the authors went on to suggest practical methods for utilizing group learning in the classroom, beginning with three types of cooperative learning groups: formal cooperative learning groups, informal cooperative learning groups, and cooperative base groups. Formal cooperative learning groups last "from one class period to several weeks" and focus on "organizing material, explaining it, summarizing it, and integrating it into existing conceptual structures" (Johnson, Johnson, \& Smith, 2006, p. 1:14). According to Johnson, Johnson, and Smith, (2006) informal learning groups are shorter-lived, lasting "from a few minutes to one class period" in order to: 
focus student attention on the material they are to learn, set a mood conducive to learning, help set expectations as to what the lesson will cover, ensure that students cognitively process the material you are teaching, and provide closure to an instructional session. (p. 1.15)

Finally, cooperative base groups are "long-term (lasting for at least a year), heterogeneous groups with stable membership whose primary purpose is for members to give each other the support, help, encouragement, and assistance each needs to progress academically" (Johnson, Johnson, \& Smith, 2006, p. 1:15).

Besides describing group types, Johnson, Johnson, \& Smith offered five essential elements to successfully utilize cooperative learning in each lesson. "The first and most important element is positive interdependence," which "exists when group members perceive that they are linked with each other in a way that one cannot succeed unless everyone succeeds. If one fails, all fail” (Johnson, Johnson, \& Smith, 2006, p. 1:17). "The second essential element of cooperative learning is individual and group accountability" (Johnson, Johnson, \& Smith, 2006, p. 1:18). Both the group and each individual in the group should be responsible for achieving goals. "The third essential element of cooperative learning is to promote interaction, preferable face-to-face" (Johnson, Johnson, \& Smith, 2006, p. 1:18). It is important to encourage students to meet face-to-face, not only to work together, but to provide an academic and personal support system. Working together also helps students "become personally committed to each other as well as to their mutual goals" (Johnson, Johnson, \& Smith, 2006, p. 1:18). "The fourth essential element of cooperative learning is teaching students the required interpersonal and small group skills" (Johnson, Johnson, \& Smith, 2006, p. 1:18). 
According to the authors, cooperative learning requires students to learn "taskwork" and "teamwork." Students must be taught teamwork skills such as "effective leadership, decision-making, trust-building, communication, and conflict management" (Johnson, Johnson, \& Smith, 2006, p. 1:18). Though much work and dedication is involved in the utilization of group learning, the authors asserted, "by using cooperative learning the majority of the time you are changing the basic organizational structure of your classes to a team-based, high-performance one” (Johnson, Johnson, \& Smith, 2006, p. 1:19).

According to Middendorf and Kalish, "breaking down the walls of anonymity promotes learning" (1996, p. 3). Van Der Karr (1994) mentioned that this is especially important for community college students, as they are:

those who have the most to gain from greater academic and social involvement on campus. These students are often academically or socially disadvantaged, they are often first-generation students, and their academic and social interaction is often limited to their time in formal classes. (p. 1)

Van Der Karr (1994) studied the impact of study groups in community colleges for high content courses such as chemistry and found three major themes: collaboration, leader roles and participation, and perceived impact of groups. The community college students, despite the diversity in ages and experiences, showed a high degree of collaboration in their study groups. Van Der Karr (1994) noted four major ways students collaborated, the first of which was collective management of the groups. They decided together when to meet, who should bring what materials, and made future study plans together. Second, they shared materials such as class notes and study materials. Third, they shared knowledge by answering each others' questions, discussing points in lecture, 
and reading the text together. Finally, they provided support for each other by commiserating over confusing material, cheering each other on through the course, and encouraging each other to do their best. Van Der Karr also noted the leader roles and participation of the groups, and concluded that although each student leader led in a different style, it is ideal for the leader to be a model student instead of a teacher. Finally, Van Der Karr analyzed the perceived impact of the study groups by interviewing the students involved. Students claimed the groups improved their study skills, familiarity and comfort with course content, confidence in the course, out-of-class involvement, and interest in future study groups (Van Der Karr, 1994).

"Study groups, collaborative learning, group problem solving, and discussion of assignments can all be dramatically strengthened through communication tools" such as e-mail, discussion boards, and chat rooms (Chickering \& Ehrmann, 1996, p. 4). However, the use of learning groups must be carefully orchestrated to provide maximum benefit for all involved. Michaelsen (1998) provided three keys to using learning groups effectively: "1) promoting individual and group accountability; 2) using assignments that link and mutually reinforce individual work, group work, and total class discussions; and 3) adopting practices that stimulate give-and-take interaction within and between groups" (p. 1). In order to promote accountability, students must be prepared for group assignments. Otherwise, better students tend to carry those less prepared. Also, if students are not well-prepared to engage in group work, the group can become a social event instead of learning (Michaelsen, 1998). Three ways to promote individual accountability are to require individual assignments before beginning group work, to assign a group member to be sure all participate, and to include peer evaluations in the 
grading system (Michaelsen, 1998). Group accountability may be ensured by assigning a tangible output, followed by "prompt assessment as well as inter-group comparison" (Michaelsen, 1998, p. 1).

The second facet of using group work effectively is using "linked and mutuallyreinforcing assignments," also known as the "3S's":

1. Same problem: Individuals/groups should work on the same problem, case, or question.

2. Specific choice: Individuals/groups should be required to use course concepts to make a specific choice.

3. Simultaneously report: Whenever possible, groups should report their choices simultaneously. (Michaelsen, 1998, p.1)

The third key to using group work effectively is to adopt practices that stimulate the exchange of ideas. According to Michaelsen (1998):

The degree to which group discussions expose students to new perspectives from their peers depends on two factors. The first factor is the extent to which the instructor uses assignments and creates conditions that foster give-and-take group interaction. The other factor is the diversity of opinions, ideas, and perspectives that exist within each group. (p.2)

The first way to ensure new perspectives is to use assignments which require group interaction. Many assignments, such as drills or worksheet completion, are easier to complete individually, so students will split the assignment and complete the tasks by themselves. Second, it is important to remove barriers to participation by assigning roles or by assigning permanent groups to increase group cohesiveness. Third, the majority of 
group work must be assigned in class, because most students will meet outside of class long enough to assign tasks, but not truly work together. Finally, it is important to assign diverse groups by making them large groups of five to seven students and choosing groups according to individual strengths and weaknesses (Michaelsen, 1998).

It is important to allow for debriefing after group activities, as this is when most of the substantive learning will occur. Professors and students can use this time to draw conclusions and summarize the lesson (Middendorf \& Kalish, 1996, p. 4). This is also when the inter-group comparisons mentioned by Michaelsen occured so that students may get immediate feedback on their work. Questions are answered during this period and the lesson is brought to a close. Michaelsen mentioned this stage in his three part model for student engagement: Individual Work + Small Group Discussion + Total Class Discussion $=$ Impact on Learning $(1998$, p. 1). Following these steps allows for a complete, rich learning experience in the classroom.

\section{Active Learning}

There are many definitions for the term "active learning" in the literature. However, a comprehensive and inclusive definition comes from Bonwell and Eison's book on active learning. They defined active learning as a brief list of characteristics "commonly associated with the use of strategies promoting active learning in the classroom" (Bonwell \& Eison, 1991, p.2). The list includes:

- Students are involved more than listening.

- Less emphasis is placed on transmitting information and more on developing students' skills.

- Students are involved in higher-order thinking (analysis, synthesis, evaluation). 
- Students are engaged in activities (e.g., reading, discussing, writing).

- Greater emphasis is placed on students' exploration of their own attitudes and values (p.2).

Middendorf and Kalish asserted that students "have an attention span of around 15 to 20 minutes and that university classes are scheduled for around 50 to 75 minutes" (1996, p. 2). Using active learning instead of hour-long lectures "lets you give your students opportunities in class to practice with the concepts you want them to learn" (Middendorf \& Kalish, 1996, p. 3). Active learning also allows for growth in both faculty and students (Jones \& Duffy, 1991). As faculty learn new methods of implementing active learning, not only do students benefit, but faculty see their material from multiple vantage points, allowing for deeper understanding of material. Bonwell and Eison (1991) provided examples of active learning strategies including the modified lecture, questioning and discussion, visual-based instruction, writing in class, problem solving, computer-based instruction, cooperative learning, debates, drama, role playing, simulations, and games, and peer teaching. The modified lecture section discussed approaches to using lectures to stimulate active learning. Pausing for enhanced retention and comprehension, tests and quizzes, demonstrations, alternative formats for lectures, and student-generated questions were the methods chosen by Bonwell and Eison. Special considerations for large class sizes were also discussed. This is valuable information, as general science courses tend to be large classes. Bonwell and Eison asserted that active learning can be used in large classes, but techniques must be modified to be applicable to more students with less faculty contact. Written questions by the student, interactive 
lectures, and small groups are possible ways to incorporate large groups in active learning.

Questioning and discussion, according to Bonwell and Eison (1991), require "careful planning, thoughtful implementation, and a supportive classroom environment, and requires an instructor's knowledge of techniques of questioning and strategies and styles for involving discussion" (p. 21). Careful planning involves deciding on appropriate and helpful discussion material, types of questions, and techniques of questioning. Discussion strategies aid thoughtful implementation of course material. Successful discussions are comprised of predetermined objectives for a class period, ask questions appropriate to material, and then provide demonstrations of techniques that are designed to challenge yet support students. A supportive classroom environment is "more than merely having the skills that encourage students to participate and learn in the classroom. More important, instructors must create an intellectual and emotional climate that encourages students' taking risks" (p. 22). Bonwell and Eison cited such behaviors as warmth, openness, predictability, and focus on student-centered learning as important to creating a supportive classroom environment. They also stated that memorizing students' names, asking them to fill out biographical note cards, and requiring office visits add to a welcoming classroom atmosphere.

Visual-based instruction is an area of contention in the literature. According to Bonwell and Eison (1991), "simply viewing a 50-minute film or videotape does not actively involve students any more than listening to a 50-minute lecture" (p. 33). It is important that students have a more interactive experience with visual-based instruction. Pierce and Jones (1998) discussed anchored instruction as a way to use video in an 
effective matter by using interactive videodiscs that require student response to questions throughout the storyline. Piburn et al. (2005) created computer-based visualization modules to enhance students' spatial ability in an introductory geology course. Spatial ability is correlated with success in science courses, so it is an important area to explore (Piburn et al., 2005). Piburn et al also ascertain:

Rather than working from dull and uninteresting workbooks, students need to be engaged actively in realistic settings that are like those experienced by geologists themselves. Rather than dealing entirely in verbal forms of learning, they should engage all of the mental faculties, including but not limited to spatial visualization. (p. 525).

Unfortunately, "although the media have high potential, their actual acceptance and use in the classroom have been significantly less than its proponents have envisioned" (Bonwell \& Eison, 1991, p. 35). Writing in class, encouraged by the Writing across the Curriculum movement, promoted tasks such as "keeping journals, focusing thoughts on particular topic, summarizing a lecture or assigned reading, or composing an essay describing the solution to a problem presented in class" (p. 35). A common theme throughout literature is that writing assignments improves student writing skills and learning. However, Bonwell and Eison were more cautious in their approach to writing in class, stating that it may be used to promote active learning when it is "tied to explicit goals of the course and other appropriate instructional methods" (p. 37). In order for writing in class to be successful, instructors must exert significant effort to plan objectives, provide writing practice, and provide feedback and coaching to the students (Bonwell \& Eison, 1991). 
Bonwell and Eison discussed problem solving relative to two approaches: case studies and guided design. Case studies "are written objectively and include a brief overview of the situation along with descriptive information that both establishes a context for the problem and identifies the major decisions that must be made" (Bonwell $\&$ Eison, 1991, p. 39). They “can range from a highly structured exercise to a very unstructured problem that could raise a variety of complex issues and alternative solutions" (Bonwell \& Eison, 1991, p. 39). One must be careful when utilizing case studies on an undergraduate, especially an introductory level, as cases must be presented within the students' experiential framework. Case studies are beneficial, as they help to "bridge the gap" between classroom learning and real life, but they also have drawbacks including student-perceived ambiguity and lack of ability to articulate.

Guided design has ten steps as recommended by Wales and Nardi (1982):

1. Outline situation

2. Define goals

3. Gather information

4. Suggest possible solutions

5. Establish constraints

6. Choose solution path

7. Analyze factors needed for solution

8. Synthesize solution

9. Evaluate solution

10. Make recommendations. 
Each step helps the students reach a solution to a curriculum-related problem presented by the instructor. The process may take several days or several weeks, but is to be supplemented with out-of-class assignments such as readings or research. When used in class, the students complete each step and then receive feedback on their ideas and performance from the instructor. The process of using guided design "helps students become more intentional and skillful when solving problems (Bonwell \& Eison, 1991, p. $41)$.

Computer-based instruction is quickly gaining ground as a viable alternative to traditional lecture. No longer do students need to rely solely on laboratory experiences and lectures to learn course material. "Apprentice-like learning has been supported by many traditional technologies: research libraries, laboratories, art and architectural studios, athletic fields" (Chickering \& Ehrmann, 1996). Statistical research, computerbased music, and "dry" simulated laboratories are a few examples of the use of technology to promote active learning (Chickering \& Ehrmann, 1996).

As more computer-literate students enter college, the expectation and need for computer-based instruction continues to grow. According to Deden and Carter (1996), there are five reasons driving colleges and universities to incorporate computer-based instruction. The first reason is the widespread use of the World Wide Web for research, both by students and faculty. It provides a method of immediate and up-to-date information that has become important not only to higher education, but to society as a whole (Deden \& Carter, 1996). The second reason is computer-based simulations provide realism and job-transferability that traditional paperwork may not. According to Deden and Carter, "from lab simulations in biology, chemistry, and physics to election 
simulations in the social sciences, these powerful tools help students learn both course content and problem-solving skills" (p. 81). The third reason is "new communications skills, such as international e-mail etiquette and nonlinear multimedia document creation, are being emphasized by employers as prerequisites for employment" (Deden \& Carter, 1996, p. 81). Computer-based instruction also meets the needs of traditional, working, and non-traditional students by removing barriers to learning such as time and location, which is the fourth reason computers are becoming widely used (Deden \& Carter, 1996). Finally, the fifth reason to include computer-based instruction is "pedagogical improvement and faculty renewal can be both simulated and supported by these technologies" (Deden \& Carter, 1996, p. 82). Technology can accomplish many goals in the classroom, such as shortening lectures, making abstract concepts concrete, and providing hands-on learning. Computer-based instruction is useful outside of the classroom as well, providing discussion, mentoring, and coaching time, practice exercises, and faster feedback (Deden \& Carter, 1996). Current utilizations of computerbased instruction include virtual field trips, learning modules, and lecture notes, among other uses. Possible drawbacks of computer-based instruction include lack of a pedagogical rationale and focus, lack of investment in people to run the technology, and focus on inappropriate problems (Deden \& Carter, 1996). Without a pedagogical rationale and focus, technological equipment may be purchased with no clear goals for its intended use; this may lead to underutilization of the technology. A support staff is required to run large-scale technology implementations such as course redesign. Faculty may need guidance and instruction in utilizing computers in this way, and without appropriate support staff, the plans to redesign will fail. Focus on inappropriate problems 
involves focus on outcomes technology cannot produce. For example, technology cannot necessarily reduce program delivery costs or computing support costs (Deden \& Carter, 1996).

There are two goals when utilizing cooperative learning as active learning: "to enhance students' learning and to develop students' social skills like decision making, conflict management, and communication" (Bonwell \& Eison, 1991, p. 43). There are many resources on cooperative learning (or group learning, or collaborative learning) in the literature, which are discussed in the previous section of the literature review.

Debates have many possible benefits, including "possibly reducing the bias an instructor might bring to the course, forcing students to deal with their own biases, enhancing students' skill in research, promoting logical thinking, increasing skill in oral communication, and motivating students" (Schroeder \& Ebert, 1983). There are multiple ways of encouraging debates in the classroom, such as formal debates with formal presentations and rebuttals, or informal class discussions including both sides of the debate (Bonwell \& Eison, 1991). Debates are traditionally used to discuss controversial issues; they are not often used in science classrooms. A possible utilization of debates in the science classroom could involve organizing scientific statements solicited from student statements, presenting them without comment to the class, and allowing the students to vote for or against each statement with appropriate arguments.

Drama is not typically utilized in the science classroom, but it is a method of utilizing active learning in the classroom. Drama does not include role playing, but instead is the use of pre-written scripts to emphasize a point (Bonwell \& Eison, 1991). 
Mainly used in arts education, "the focus is on understanding the subtext, setting, use of music and art, and any other sociocultural factors" (Pierce \& Jones, 1998, p. 86).

Role playing, simulations, and games are other methods of incorporating active learning in teaching. Role playing, as defined by Bonwell and Eison (1991), are "sessions that last less than an hour, while simulations and games can last several hours or even days" (p. 47). "Further, simulations and games (which can include role playing) are defined more precisely than are role plays (which often are spontaneous) and include guiding principles, specific rules, and structured relationships" (Bonwell \& Eison, 1991, p. 47). Role playing allows students to examine their own attitudes, biases, and prejudices toward others and circumstances different from their own (Bonwell \& Eison, 1991).

Peer teaching, sometimes considered a part of cooperative or group learning, is also known as peer tutoring (Bonwell \& Eison, 1991). Whitman (1988) classified peer teachers into five groups: teaching assistants (undergraduate and graduate), peer tutors, peer counselors, partnerships, and working groups. Partnerships, where each student partner alternates teaching/learning roles, and working groups most exemplify active learning in the classroom (Bonwell \& Eison, 1991). There are many opportunities to use peer teaching in the science classroom, including laboratory work, problem solving, and reading for meaning exercises.

Barriers to active learning are difficult to overcome. Bonwell and Eison (1991) included:

1 One cannot cover as much content in the time available; 
2 Devising strategies promoting active learning takes too much preparation before class;

3 Large classes prevent implementation of such strategies; and

4 Materials or equipment needed to support active learning are lacking. (p. 59)

Zoller (1999) mirrored some of these concerns in his study involving using active learning in organic chemistry lecture. He mentioned issues such as demanding chemistry pedagogies and room and class size as being barriers for active learning. According to Zoller (1996):

In the scaling-up of such teaching strategies, at least two major tradeoffs were apparent: (a) there was insufficient time available for the formal full coverage in class of the entire course topics as requested by the syllabus; and (b) there was not a high appreciation by the students of the teaching effectiveness that they experienced, particularly in view of their conditioned expectations from teaching. (p. 588).

In conclusion, O'Sullivan and Copper stated that "encouraging students to formulate their own ideas, draw conclusions from experimental evidence, and participate in other similar activities can be more effective" than traditional lecture (2003, p. 448). Bonwell and Eison (1991) agreed, stating "that most of these (active learning) strategies have been shown to deliver content as well as lectures [sic] while providing diverse presentations that enhance students' motivation and achievement" (p. 52). 


\section{Giving Prompt Feedback}

It is important to both student learning and student motivation that students understand what they know and what they still need to learn in order to master a course or subject area. Sorcinelli wrote, "Students need prompt feedback on performance to benefit from courses. Such feedback can include diagnosis at the beginning of a semester, frequent tests with prompt feedback throughout the term, and assessments at various points during college" (1991, p. 18). According to Chickering and Ehrmann (1996), students need help assessing their current knowledge at the beginning of a course. During class meetings, students need ongoing opportunities to demonstrate their knowledge and receive feedback on their work (Chickering \& Ehrmann, 1996). This not only applies to particular courses, such as chemistry, but also to the college experience as a whole. It is important for students to understand what they have gained from their postsecondary learning experiences.

Shulman suggested "embed(ding) assessment into ongoing instruction” (2007, p. 24). "Assess early and assess often...the later the assessment, the later the knowledge of the results, and the less likely it is that the assessments will yield information that can guide instruction and learning" (Shulman, 2007, p. 24). He suggested using forms already in place in education and society, such as "running records" used by elementary and secondary educators, routine medical histories, or laboratory tests. "When we embed assessment in instruction, it is much more likely that what is assessed will contribute to and be compatible with the core objectives of instruction" (Shulman, 2007, p. 24). Ideally, according to Shulman (2007), these embedded assessments: 
will be more particular than general; more dedicated to measuring individual student progress than institutional success; repeatedly administered rather than being single end-of-course events; and highly transparent to students and teachers. They will have quick turn-around times rather than providing the highly secure, secretive, and delayed feedback of current high-stakes environments. (p. 24). Parkland College in Illinois utilized embedded assessment by training instructors in using classroom assessment techniques (CATs) in their courses (Rouseff-Baker \& Holm, 2004). CATs are "quick, simple, and usually anonymous tools that help to gather feedback from students on their learning” (Rouseff-Baker \& Holm, 2004, p. 30). Parkland taught its instructors to use CATs with the six-step Feedback Loop: Plan, Teach, Assess, Analyze, Respond, and Adapt (Rouseff-Baker \& Holm, 2004). Instructors at that institution have used the Loop not only to get information about learning in their own classrooms, but to apply their results to entire programs of study and departments. According to Rouseff-Baker and Holm (2004), one of the great benefits of this type of quick assessment (besides fast turn-around) was that:

students are invited to be part of gathering, assessing, analyzing, and acting upon the evidence that they provide. When students complete a CAT and hear the results from their instructor, they are involved in the process of metacognition: thinking about thinking and learning. (pp. 31-32).

Technology can be utilized to facilitate prompt feedback in myriad ways: email for direct teacher-to-student contact, measures of performance, such as with pertinent "apprentice" software, editing functions such as those in Microsoft Word, and portfolio work (Chickering \& Ehrmann, 1996). Email is a commonly used method for asking 
instructors questions and for receiving grades and comments, especially in online courses. It is private, but unfortunately can easily be misread. A gentle criticism can be read as a hateful attack in this format. Apprentice software, such as chemical modeling software or engineering modules, can also be an effective method of prompt feedback, allowing the computer program or the instructor to offer feedback. The computer program may offer it immediately after a module is finished, or the instructor may view the students' work and then offer comments. Editing functions allow an instructor to place comments and corrections directly in a document and can be easily turned off, preventing embarrassment for the students should a multitude of red marks exist. Portfolios that are stored online or on computers may be tracked for improvement and comments, and provide easy access for ongoing feedback.

\section{Emphasizing Time on Task}

Time management skills are essential to every aspect of modern life, whether it be in the educational, professional, or personal realm. "Learning to use one's time well is critical for students and professionals alike" (Chickering \& Ehrmann, 1996, p. 1). Effective time management in the classroom is vital to improving student learning, as "the learning time is a major determinant of the amount of content comprehended" (Myers, 1990, p. 1). Unfortunately, "much of the time allocated for instruction in a class is spent on preliminary administrative activities" as well as other non-learning activities (Myers, 1990, p. 1). According to Metzker (2003), "opportunity for student learning can be increased by ensuring that teachers are employing effective classroom-management strategies" (p. 1). It is important that time on task is maximized because according to a study by Bracey (2001), "students with good grades were more engaged than students 
with poor grades; and at-risk students were less engaged than students not judged to be at risk" (p. 555). Bracey also found that students were most engaged in courses such as science and mathematics and less engaged in courses such as English and the social sciences. Also, "students were substantially more engaged during discussions, lab work, group work, and when receiving individualized instruction" (Bracey, 2001). Student engagement (and therefore time on task) was found to increase during "instruction that students found relevant to their lives, instruction that was academically challenging, and instruction that made more academic demands" (Bracey, 2001, p. 555).

Technology is helpful in emphasizing time on task by making coursework more attractive, more efficient, and assisting classroom research (Chickering \& Ehrmann, 1996). Chickering and Ehrmann (1996) quoted a faculty member as using technology to "steal students' beer time" by "attracting them to work on course projects instead of goofing off' (p. 1). Computer work, such as simulations and immediate-feedback quizzes, are attractive to students who utilize the computer in everyday life. It is perceived as faster and easier than poring over books and going to the library to complete coursework. Technology can also be utilized to make coursework more efficient.

Distance learning and online modules for courses that may help students study at home or even at work can "save hours otherwise spent commuting to and from campus, finding parking places, and so on" (Chickering \& Ehrmann, 1996, p. 1). Options such as email and message boards also allow learning to fit into busy schedules of both instructors and students, making it more efficient for many people. It is important that instructors emphasize the importance of time-on-task, because "the remoteness or distance of cyberinstructors may diminish any sense of urgency on the part of their students to spend 
time completing Web-course assignments" (Newlin \& Wang, 2002, p. 327). Postings and deadlines should appear online regularly to remind students to stay on task with coursework. Online libraries and other research methods also allow students to perform research anywhere, thereby making better use of their time. Faculty interested in researching time on task can also utilize computers to track participation and interaction.

\section{Communicating High Expectations}

"Specifying expectations is simply identifying the reasonable steps to follow in order to reach standards" (Maitland Schilling \& Schilling, 1999, p. 9). A current discussion in education literature is the lack of communication of expectations to the undergraduate population. According to Page and Mukherjee (2000), "the typical undergraduate student is apathetic about education" (p. 548). The students become apathetic when they "perceive... insurmountable hindrances in the pursuit of academic excellence" (Page \& Mukherjee, 2000, p. 548). Some of these hindrances include managing academics along with work and family, balancing extra-curricular activities with academics, perceived lack of relevance of course work, and difficulty in adjusting to different teaching styles. They state that the educational goal for many students is to achieve a "C" grade and get a degree. This grade generally means that the students "merely met the requirements of a course" and miss many benefits of higher education, such as job preparation (Page \& Mukherjee, 2000). Students also do not expect to spend an appropriate amount of time on schoolwork outside of the classroom, thereby contributing to less learning. According to Maitland Schilling and Schilling (1999), "faculty state that two to three hours of work outside of class for every hour in class is 
necessary to succeed, yet entering students report expecting to spend about a third of that time" (p. 5).

When faculty confront problems with implementing strategies to focus on student learning, a common obstacle is that "faculty's expectations for students are often never clearly defined beyond the institutional level" (Barrowman, 1996, p. 106). Maitland Schilling and Schilling (1999) agreed, stating "few higher education institutions have publicly articulated clear, high expectations of the knowledge, skills, and capacities students are to attain" (p. 5). The outcome of this is students who come to college with expectations of learning that are "at best vague and uninformed, or worse, wildly divergent from the expectations that faculty and staff hold for them" (Maitland Schilling \& Schilling, 1999, p. 5). Maitland Schilling and Schilling explained that these false expectations are formed by high school experiences, where students are not expected to spend as much time and energy on educational experiences (1999).

According to Barrowman (1996), when educators make public their "expectations for student learning" and "use those expectations to navigate...teaching... students are better prepared for life in and beyond the classroom" (p. 104). She goes on to state, "student abilities articulated in public criteria shape the pedagogy in our courses and programs. This principle results in student learning that can be measured through assessment and self-assessment" (Barrowman, 1996, p. 106). Maitland Schilling and Schilling (1999) asserted:

Without a shared institutional understanding of reasonable expectations for student academic effort and investment of student time and effort in appropriate activities, 
aspirations for enhancing the impact of colleges and universities on student learning must remain modest at best. (p. 6).

Students will make more progress toward educational goals when they fully understand what they are supposed to learn and when classroom experiences are designed to align with those expectations (Barrowman, 1996). The Wingspread Group (1993) concurred with this thesis, offering seven steps to achieving "putting learning first" by setting high academic expectations:

- "understand their mission clearly and define the kinds of students they can serve best;

- define exactly what their entering students need to succeed;

- start from where the students begin and help them to achieve explicitly stated institutional standards for high achievement;

- tailor their programs - curriculum, schedules, support services, office hours - to meet the needs of the students they admit, not the convenience of staff and faculty;

- $\quad$ systematically apply the very best of what is known about learning and teaching on their campuses;

- rigorously assess what their students know and are able to do in order to improve both student and institutional performance; and

- develop and publish explicit exit standards for graduates, and grant degrees only to students who meet them" (p. 13).

When defining expectations, it is vital that they be detailed and "contextualized in some of the content and processes" of the subject area (Barrowman, 1996, p. 108). 
Expectations must also "be an integration of the knowledge and the abilities necessary in the performance" (Barrowman, 1996, p. 110). Technology can be effective in communicating higher expectations for students. "Significant real-life problems, conflicting perspectives, or paradoxical data sets can be powerful learning challenges that drive students to not only acquire information but sharpen their cognitive skills of analysis, synthesis, application, and evaluation" (Chickering \& Ehrmann, 1996). Some instructors use the motivation of having student work on the Internet as incentive for thorough work, as well as peer evaluation as motivation (Chickering \& Ehrmann, 1996).

Examples of institutions effectively implementing higher expectations are discussed by Maitland Schilling and Schilling (1999); Indiana University Purdue University Indianapolis (IUPUI), Chicago State University, and Xavier University are some institutions mentioned. IUPUI, for example, has instituted "resource-intensive first-year seminars" with the intention of "clearly communicat(ing) institutional expectations and shap(ing) student expectations for their academic involvement" (Maitland Schilling \& Schilling, 1999, p. 7). Chicago State University has used assessment plans to link expectations into the curriculum at all levels. Xavier University used faculty retreats to examine "data from students and faculty on academic expectations" to further ingrain expectations into the academic culture (Maitland Schilling \& Schilling, 1999, p. 7). Jones (2002) profiled many initiatives and institutions in her report and stated that in these cases, "faculty clearly identified the specific learning outcomes that they wanted students to master in individual courses" (p. 86). Jones also discussed professional programs that linked their learning goals to "the needs of the workplace and suggestions from employers or advisory boards," clearly communicating 
high expectations to apprentice professionals (2002, p. 86). This also made course instruction important in a real-world sense, which may help increase student performance.

Respecting Diverse Talents and Ways of Learning

According to Chickering and Ehrmann (1996), "students need opportunities to show their talents and learn in ways that work for them" (p. 1). Not all students learn in the same style and many hours of frustration can be avoided by offering varying learning and teaching styles in the classroom. Many studies and reports on learning styles have been conducted in recent literature, but the overall point is that "better acquisition of concepts is obtained when students learn in environments matching with their learning styles" (Uzuntiryaki et al, 2003, p. 10). Guild and Garger (1998) considered learning style models developed by Dunn and Dunn, Flaherty, Gregorc, and Gardner major contributors to the development of this field. Dunn and Dunn (1978) created the original Learning Preferences model with eighteen elements grouped into four types of learning stimuli. It has been modified to the current model of twenty-one elements and five types of learning stimuli. The five types of stimuli are environmental, emotional, sociological, physiological, and psychological. Elements within include sound, light, temperature, and room design for environmental stimuli; motivation, persistence, responsibility, and structured planning for emotional stimuli; working with pairs, adults, peers, groups, self, and variety for sociological stimuli; perceptual strengths, time of day, intake, and mobility for physiological; and global/analytic, impulsive/reflective, and right/left hemispheric brain dominance for psychological (Tendy \& Geiser, 1997). Flaherty (1992) devised the Learning Modalities model with four major modalities: kinesthetic, tactile, 
auditory, and visual. She applied characteristics to each modality, including "learn by doing" for kinesthetic learners and "focus on non-verbal communication" for tactile learners (Tippett, 2003, p. 27). The Gregorc Model suggested that acquiring information is either concrete or abstract and processing information is either random or sequential. There are four combinations of these components including concrete random, concrete sequential, abstract random, and abstract sequential. Each combination has specific characteristics; for example, abstract random learners do not like routine, while abstract sequential thrives with order and step-by-step directions (Gregorc, 1985). Gregorc further believed that all learners have aspects of each type, but tend to have one dominant combination (Gregorc, 1984).

The final model considered by Guild and Garder is one of the most familiar to educators: Gardner's Multiple Intelligences. First introduced in 1983 in Frames of Mind, Gardner suggested seven different intelligences: linguistic (ability to understand and use spoken and written communication), musical (ability to understand and use musical concepts), logical-mathematical (ability to understand and use logic and numerical symbols and operations), spatial (ability to orient and manipulate three-dimensional space), bodily-kinesthetic (ability to coordinate physical movement), interpersonal (ability to understand and interact well with others), and intrapersonal (ability to understand and use one's own thoughts and feelings). Two recently added intelligences include naturalistic (ability to distinguish and categorize objects or phenomena in nature) and existential (ability to contemplate phenomena or questions beyond sensory data) (Moran, Kornhaber, \& Gardner, 2006, p. 25). Students generally possess multiple intelligences in one of two ways: laser profile and searchlight profile. The laser profile 
student is very strong in one or two intelligences and considerably weaker in the others; the searchlight profile student has relatively small differences in strengths between intelligences (Moran, Kornhaber, \& Gardner, 2006). Gardner (2006) and his colleagues believed:

The multiple intelligences approach does not require a teacher to design a lesson in nine different ways so that all students can access the material. Rather, it involves creating rich experiences in which students with different intelligence profiles can interact with the materials and ideas using their particular combinations of strengths and weaknesses. (p. 27).

Uzuntiryaki, Bilgin, and Geban (2003) conducted a study on high school students' learning styles and achievement and attitudes in chemistry. Not surprisingly, their results indicated that "learning style has an influence on students' achievement and attitudes," and students with independent learning styles tend achieve more in chemistry with a better attitude (p. 9). The authors also suggested that "educators should identify students' learning styles and design strategies based on students' learning styles to improve learning” (p. 10). While identifying each student's learning style in a large lecture section may be impossible, instructors can be sure to include multiple teaching and learning strategies to incorporate all learners. Uzuntiryaki, Bilgin, and Geban (2003) suggested:

For independent learners who like to study alone, teachers may use case studies, cognitive maps, panels, self-discovery activities, small group work teams, student teacher methods, or role playing. For dependent learners who prefer to study with 
peers and views the teacher as a source of knowledge, teachers may use lectures, teacher-centered discussions, tutorials or role modeling. (p. 10).

Drysdale, Ross, and Schulz (2001) conducted a study of college students that compared their Gregorc learning style with their grade point averages. The results indicated a significant relationship between learning style and grades, particularly in science and math-related courses. Sequential learners, or those who tend to observe the world in a concrete manner, tend to perform better in science and math courses, especially in chemistry. This includes both concrete sequential (CS) learners and abstract sequential (AS) learners, who achieved the majority of A's in the general chemistry course studied. CS learners are "practical, predictable, to-the-point, organized, and structured," while AS learners are "intellectual, logical, conceptual, rational, and studious" (Drysdale, Ross, \& Schulz, 2001, p. 274). These Gregorc styles are similar to the styles used in Uzuntiryaki, Bilgin, and Geban's study, and echo the idea that independent, logical, and organized students tend to do better in chemistry.

There are many ways to incorporate multiple learning styles into a chemistry course. Besides lecture and group activities, the laboratory is an exceptional method of teaching to multiple intelligences. Laboratory is effective because "hands-on experiences take into account the learning styles of most of the participants" (Manner, 2001, p. 392). Technology can help students by requiring many types of knowledge and methods of learning in exercises. Different methods of learning can be displayed "through powerful visuals and well-organized print; through direct, vicarious, and virtual experiences; and through tasks requiring analysis, synthesis, and evaluation, with applications to real-life situations" (Chickering \& Ehrmann, 1996, p. 1). Also, technology can be used to require 
reflection on one's preferred ways of knowing and to participate in group problem solving (Chickering \& Ehrmann, 1996). Distance learning courses and online coursework can also allow students to move at their own pace to complete assignments, letting them feel comfortable with their progress and learning styles. According to Newlin and Wang (2002):

It should be evident that the creative use of Web-based technologies can support the diverse ways of knowing exhibited by cyberstudents. In addition to a textbook, cyberstudents can select from a rich array of Web resources to master the content of a course. (p. 328-329).

Online courses allow students with personal circumstances such as physical disabilities, family responsibilities, and travel requirements to complete coursework from home (Newlin \& Wang, 2002).

In conclusion, the Seven Principles of Good Practice in Undergraduate Education is a well-researched, time-tested method of determining the effectiveness of undergraduate education. By implementing the seven principles, instructors ensure their students are receiving a well-rounded education that includes student-faculty contact, cooperation among students, active learning, prompt feedback, appropriate time on task, high expectations, and appreciation for diverse learning abilities. It is important that instructors, especially in the sciences, familiarize themselves with the principles in order to improve student achievement. 


\section{CHAPTER 3}

Method

\section{Population}

The population for this study consisted of all general chemistry instructors at associate's colleges in the United States, both full- and part-time. According to the Carnegie Foundation (2008), there were 1,046 regionally accredited associate's colleges where the population of chemistry instructors reside. Accredited institutions were studied because the voluntary accreditation process ensures relatively uniform college practices. This made the institutions comparable for this study. Four of the six accreditation regions were used in this study to maintain a tighter geographical focus region. An Internet search was performed on those institutions listed on the Carnegie Foundation's website, and those with insufficient contact or program information were not used in the study.

\section{Research Design}

A quantitative research approach was utilized to answer the research questions presented in Chapter 1. The quantitative survey that guides this study served as the research design. The Faculty Inventory of the Seven Principles for Good Practice in Undergraduate Education from the Wingspread Group was used without modification for the current research (see Appendix A). It was developed after "the enthusiastic response to the Seven Principles" as a "self-assessment instrument for faculty members, with examples and indicators of each of the principles" (Gamson, 1991, p. 9). The inventory was developed by collecting hundreds of examples of uses of the Seven Principles "from participants in workshops, from other instruments, from publications, and 
from...experiences" and setting clear criteria for choosing appropriate items from the examples (Gamson, 1991, p. 9). A group of researchers met to choose items according to the following criteria: "applicable to a range of disciplines, institutions, and class settings; short and jargon free; and focused on behavior or practices that could be changed" (Gamson, 1991, p. 9). After the committee chose the items, a draft of the inventory was sent to a wide range of institutions. After 250 respondents reacted to the inventory, the committee revised the survey as appropriate. The current version of the survey consists of seven sets of ten questions, each set concerned with one of the seven principles. This version was "designed and published in fall 1989 by the Johnson Foundation" and is the version used in this study (Gamson, 1991, p. 10).

\section{Data Collection}

Data were collected through an online survey that was e-mailed to all participants. The initial e-mail included the cover letter (see Appendix B) and a link to complete the survey on SurveyMonkey.com. There was a two-week return time which will be stipulated in the cover letter and two reminder e-mails were sent out to nonrespondents. Demographics included full-time/part-time status, sex, class size, years teaching experience, highest degree awarded, and typical student population (full-time or parttime). The survey, entitled "Faculty Inventory of the Seven Principles for Good Practice in Undergraduate Education," includes 5-point Likert scales and open-ended questions.

\section{Utilization of Survey Data to Answer Research Questions}

Upon receiving completed surveys, data were uploaded into SPSS. Results were compared utilizing the descriptive, comparative, and ANOVA functions of SPSS. 
In order to answer research questions posed in Chapter 1, SPSS data will be utilized. If any main effects or interactions yield a significant finding, multiple comparisons (post-hoc tests) will be computed via the Tukey test.

1. To what degree were community college chemistry faculty using Chickering and Gamson's (1991) Seven Principles of Good Practice in Undergraduate Education?

a. Encouraging student-faculty contact

b. Encouraging cooperation among students

c. Encouraging active learning

d. Giving prompt feedback

e. Emphasizing time on task

f. Communicating high expectations

g. Respecting diverse talents and ways of learning

This research question was answered using frequencies and percentages for the Likert scale responses for each question. For example, the responses were coded in SPSS as 5 meaning "very often" and 1 meaning "never," as suggested by Suskie (1996). So, for survey item number one, "I advise my students about career opportunities in their major field," if 60 percent of respondents indicated they often or very often did this, it would be assumed that most instructors carried out this activity. All ten survey items per principle were analyzed in this way, delineating which survey items faculty members performed or did not perform.

2. Was there a significant difference in principle utilization by type of principle?

a. Faculty-student contact (50 to 10)

b. Cooperation among students (50 to 10) 
c. Active learning (50 to 10$)$

d. Prompt feedback (50 to 10$)$

e. Time on task (50 to 10$)$

f. High expectations (50 to 10$)$

g. Respect diverse talents and ways of learning (50 to 10)

This question was answered by comparing means of each set of survey items, thereby comparing each of the seven principles. To compare the seven principles, each set of ten survey items per principle was summed for each individual. This provided a "total score" with a range of 10 to 50 for each principle. For example, a score of 50 suggests that an individual faculty member very often performed all ten actions in regard to a specific principle. By contrast, a score of 10 suggests an individual faculty member never performed those ten actions in regard to a specific principle. Means and standard deviations of the total scores for each principle were determined, and $t$-tests were computed to explore differences among the seven principles. Statistical significance findings were indicated at the $p<.05$ and $p<.01$ levels.

3. Is there a significant difference in utilization of principles by accreditation region?

a. The Middle States Association of Colleges and Schools

b. The New England Association of Schools and Colleges

c. The North Central Association of Colleges and Schools

d. The Southern Association of Colleges and Schools

This research question was answered by comparing the means for each set of survey items across the four of the six accreditation regions. For example, if for the facultystudent contact set of items averages to 40.5 in the Southern Association and 20.3 in 
the North Central Association, it can be assumed that faculty in the northwest do not currently utilize faculty-student contact as much as in the south. To determine if there were statistically significant differences in utilization of the Seven Principles across the four Accreditation Regions, a MANOVA and subsequent ANOVAs were computed. That analysis had one between-subjects independent variable (Accreditation Regions) crossed with one within-subjects independent variable (Seven Principles). For the between-subjects independent variable, different participants (people) were in each of the four Accreditation Regions. For the withinsubjects independent variable, every participant (person) responded to all of the Seven Principles. The ANOVA was structured to take into account the differential variances from the "between" and the "within" independent variables. The dependent variable was mean total scores that ranged from 50 (very often) to 10 (never).

4. Is there a significant difference in utilization of principles by gender of chemistry instructor?

This research question was answered by comparing the mean total scores for the seven principles in terms of male and female respondents. To determine if there were statistically significant differences in utilization of the Seven Principles between genders, a MANOVA and subsequent ANOVAs were computed. That analysis had one between-subject independent variable (gender) crossed with one within-subjects independent variable (Seven Principles). For the between-subjects independent variable, different participants (people) were one of two genders (male or female). For the within-subjects independent variable, every participant (person) responded to all of the Seven Principles. The ANOVA was structured to take into account the 
differential variances from the "between" and the "within" independent variables. The dependent variable was mean total scores for each principle, ranging from 50 (very often) to 10 (never).

5. Is there a significant difference in utilization of principles by class size (small, medium, large)?

This research question was answered by comparing mean total scores for the seven principles across the three class sizes. To determine if there were statistically significant differences in utilization of the Seven Principles across the three class sizes, a MANOVA and subsequent ANOVAs were computed. That analysis had one between-subject independent variable (class size) crossed with one within-subject independent variable (Seven Principles). For the between-subject independent variable, different participants (people) selected one of three class sizes (small, medium, large). For the within-subject independent variable, every participant (person) responded to all of the Seven Principles. The ANOVA was structured to take into account the differential variances from the "between" and the "within" independent variables. The dependent variable was mean total scores ranging from 50 (very often) to 10 (never).

\section{Limitations of Study}

The first limitation of this study was that it will not reveal how students responded to the methods instructors utilized in the classroom. The second limitation is that the response rate may have been low due to the length of the survey; however, the entire survey had to be utilized in order to maintain the integrity of Chickering and Gamson's original work. All of the Likert questions were on a 5-point scale, which may have lead 
to bias "because people are generally more inclined to agree than disagree with a statement" (Suskie, 1996, p. 33). Suskie also warns of the "yeasayer/naysayer effect," in which a person with a generally negative attitude regarding the topic will tend to fill in the "rarely" or "never" column without really reading the survey, and a person with a generally positive attitude about the topic will tend to fill in "very often" (1996, p. 34). Finally, this survey produced self-reported data, which may not be as accurate as factual data from a primary source (Suskie, 1996). 


\section{CHAPTER 4}

Results

\section{Overview}

This chapter discusses the detailed survey results. First, the survey response is reviewed, and then demographic analysis is provided to characterize the participants of the study. Data analysis is then presented by research question. The first research question queried the degree to which chemistry community college faculty utilized the Seven Principles. The second research question looked for differences in utilizations of principles by types of principle. The third research question looked for significant differences in utilization of principles by accreditation region. The fourth research question examined differences in principle utilization by gender of instructor. Finally, the fifth research question checked for differences in principle utilization by class size.

\section{Survey Response}

The researcher sent 2349 e-mail invitations to participate in the survey. Many email addresses obtained were not functional; 263 e-mail addresses bounced and many more were sent to retired instructors or to those who left their position as a community college chemistry instructor. After the initial invitation, the researcher allowed a twoweek turnaround time and re-sent invitations to non-respondents. The online survey was open a total of 20 days. Of the $415(17.7 \%)$ returned surveys, 371 participants completed the entire survey for an $89.4 \%$ completion rate.

Demographic Analysis

At the beginning of the survey, participants were asked to respond to demographic questions to characterize respondents and allow for comparisons of data. 
Gender

Nearly two-thirds of the respondents were male (see Table 1).

Table 1

Gender of Survey Respondents

\begin{tabular}{lcc}
\hline \multicolumn{1}{l}{ Gender } & $\mathrm{N}$ & $\%$ \\
\hline Male & 260 & 62.7 \\
Female & 154 & 37.1 \\
No Response & 1 & 0.2 \\
Total & 415 & 100 \\
\hline
\end{tabular}

Employment Status

For the purposes of this survey, employment status was considered either fulltime (more than 12 instructional hours) or part-time (less than 12 instructional hours) during the Spring 2010 semester. Full-time status also included those who taught at different institutions for a total of 12 hours per semester. Nearly eighty percent of faculty were full-time at the same institution (see Table 2). 
Table 2

Employment Status of Participants

\begin{tabular}{lcc}
\hline \multicolumn{1}{c}{ Employment Status } & $\mathrm{N}$ & $\%$ \\
\hline $\begin{array}{l}\text { Full-time (12 credits or more at same } \\
\text { institution) }\end{array}$ & 323 & 77.8 \\
$\begin{array}{l}\text { Full-time (12 credits or more across } \\
\text { different institutions) }\end{array}$ & 8 & 1.9 \\
Part-time (less than 12 credits) & 82 & 19.8 \\
No Response & 2 & 0.5 \\
Total & 415 & 100 \\
\hline
\end{tabular}

Class Size

This study specified class sizes as small (1 to 20 students), medium (20 to 40 students), or large (41 or more students). Two-thirds (66\%) of respondents teach predominantly medium-sized chemistry courses with relatively few respondents responsible for large classes (see Table 3). 
Table 3

Typical Chemistry Class Size of Respondents

\begin{tabular}{lcc}
\hline \multicolumn{1}{c}{ Class Size } & N & $\%$ \\
\hline Small (1 to 20 students) & 107 & 25.8 \\
Medium (20 to 40 students) & 273 & 65.8 \\
Large (41 or more students) & 35 & 8.4 \\
Total & 415 & 100 \\
\hline
\end{tabular}

Years in Higher Education

Respondents were asked to indicate the number of years they had been teaching in higher education. Possible responses ranged from 0 (beginning first year) to 21 or more years of service. Results for this demographical question were more divided than the previous responses, but more than one-half of respondents $(55.9 \%)$ were veteran instructors of more than 10 years (see Table 4). 
Table 4

Number of Years in Teaching Higher Education

\begin{tabular}{lcc}
\hline \multicolumn{1}{c}{ Number of Years } & $\mathrm{N}$ & $\%$ \\
\hline 0 (beginning first year) & 7 & 1.7 \\
1 to 5 & 70 & 16.9 \\
6 to 10 & 106 & 25.5 \\
11 to 15 & 72 & 17.3 \\
16 to 20 & 55 & 13.3 \\
21 or more & 105 & 25.3 \\
& & 100 \\
\hline
\end{tabular}

\section{Highest Degree Completed}

Instructors were asked to indicate their highest degree completed. Choices for this question were Bachelor's, Master's, Doctorate, or Other. Approximately one-half $(53.5 \%)$ of respondents obtained a Doctorate, but nearly as many instructors obtained a Master's degree $(43.6 \%)$. Only ten $(2.4 \%)$ respondents were teaching at a two-year institution with a Bachelor's degree (see Table 5). 
Table 5

Highest Degree Completed by Respondents

\begin{tabular}{lcc}
\hline \multicolumn{1}{c}{ Degree } & $\mathrm{N}$ & $\%$ \\
\hline Bachelor's & 10 & 2.4 \\
Master's & 181 & 43.6 \\
Doctorate & 222 & 53.5 \\
Other & 4 & 1.0 \\
Total & 415 & 100 \\
& & \\
\hline
\end{tabular}

Major Area of Degree

Respondents were asked to provide a general response as in which major their highest degree was completed. Choices included Science, Education, or Other. The overwhelming majority ( $81.7 \%$ ) chose Science as their major (see Table 6). 
Table 6

Major Area of Degree

\begin{tabular}{lcc}
\hline \multicolumn{1}{c}{ Major Area } & $\mathrm{N}$ & $\%$ \\
\hline Education & 26 & 6.3 \\
Science & 339 & 81.7 \\
Other & 47 & 11.3 \\
No Response & 3 & 0.7 \\
Total & 415 & 100 \\
\hline
\end{tabular}

Type of Students

Respondents were asked to specify whether the majority of enrolled students at their campus were full- or part-time. Full-time status included 12 credits or more per semester, and part-time status included fewer than 12 credits. Most respondents $(76.1 \%)$ indicated that their students enrolled in full-time status (see Table 7). 
Table 7

Typical Student Status

\begin{tabular}{lcc}
\hline \multicolumn{1}{c}{ Student Status } & $\mathrm{N}$ & $\%$ \\
\hline Full-time (12 credits or more) & 316 & 76.1 \\
Part-time (less than 12 credits) & 85 & 20.5 \\
No Response & 14 & 3.4 \\
& & 100 \\
Total & 415 & \\
\hline
\end{tabular}

\section{Regional Accreditation}

Each respondent was asked to indicate to which accreditation region their institution belonged. Four of the six accreditation regions were included: Middle States, New England, North Central, and Southern. Thirty-nine percent of respondents were from the Southern Association and thirty-three percent were from the North Central Association (see Table 8). 
Table 8

Regional Accreditation Associated with Institution

\begin{tabular}{lcc}
\multicolumn{1}{c}{$\begin{array}{c}\text { Accreditation } \\
\text { Region }\end{array}$} & $\mathrm{N}$ & $\%$ \\
\hline Middle States & 77 & 18.5 \\
New England & 17 & 4.1 \\
North Central & 136 & 32.8 \\
Southern & 161 & 38.8 \\
No Response & 24 & 5.8 \\
Total & 415 & 100 \\
& & \\
\hline
\end{tabular}

Research Question 1

The first research question asked was, "To what degree are community college chemistry faculty using Chickering and Gamson's Seven Principles of Good Practice in Undergraduate Education (Gamson, 1991)?” For each principle, there are ten survey items that characterize each principle. This research question is answered by reporting frequencies and percentages for responses to each individual question. Tables 9 through 15 include each survey item, frequencies and percentages for each potential rating. The Likert scale responses range from 5 (Very Often) to 1 (Never).

The first principle states, "Good practice encourages student-faculty contact." Faculty responded that they performed four activities important to student-faculty contact often or very often. Forty-three percent of faculty indicated they often shared their past experience, attitudes, and values with students and 41 percent very often know their 
students' names by the end of the first two weeks of the term. Over 60 percent $(63.8 \%)$ of respondents at least often make special efforts to be available to students of a culture or race different from their own and nearly one-third (30.3\%) serve as a mentor or informal advisor to students. Nearly 40 percent of faculty indicated that they occasionally advised their students about career opportunities in their major field and attended events sponsored by student groups. Almost half (46.1\%) of the participants responded that students drop by their offices occasionally. About one-third of the faculty reported rarely working with student affairs staff on student issues or helping to resolve conflict involving students on campus. One half of the respondents (50.7\%) also indicated that they never take students to professional meetings or events in the field (see Table 9). 
Table 9

Principle 1: Good Practice Encourages Student-Faculty Contact

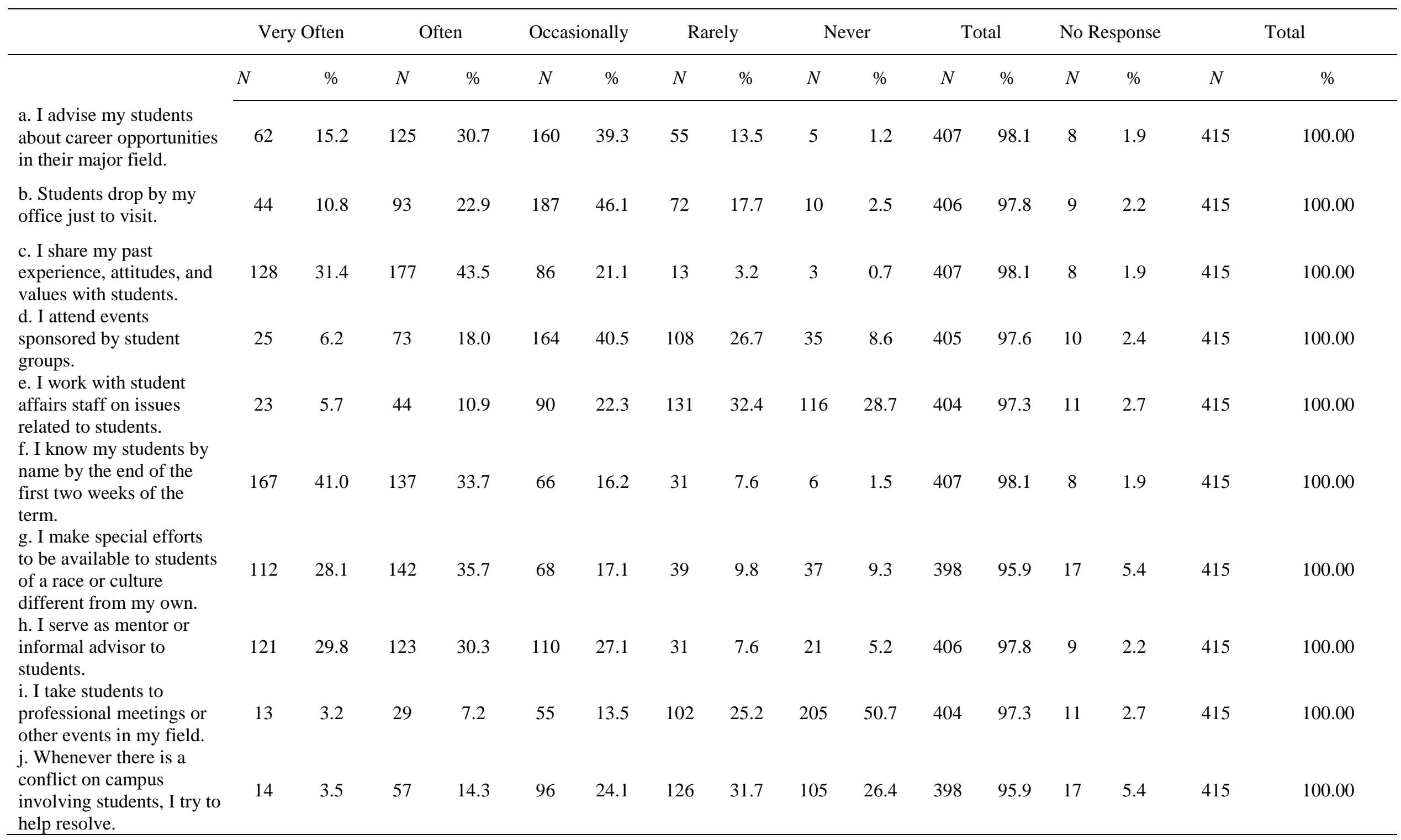


The second principle of good practice states, "Good practice encourages cooperation among students." Faculty indicated that they very often encouraged students to prepare together $(51.4 \%)$, encouraged students to do projects together $(35.7 \%)$, and distributed performance criteria to students (41.0\%). Forty percent of respondents often asked students to explain difficult ideas to one another. One-third of participants stated that they occasionally asked students to tell each other about their backgrounds, and almost 31 percent (30.9\%) occasionally asked students to evaluate each other's work. More than 36 percent (36.7\%) occasionally encouraged students to praise one another for their accomplishments, while fewer than 30 percent (26.0\%) asked students to occasionally discuss key concepts with students of backgrounds and viewpoints that differ from their own. Nearly 25 percent of respondents rarely created learning communities or study groups $(24.0 \%)$ and over half of faculty rarely or never encouraged students to join campus organizations (53.2\%) (see Table 10). 
Table 10

Principle 2: Good Practice Encourages Cooperation Among Students

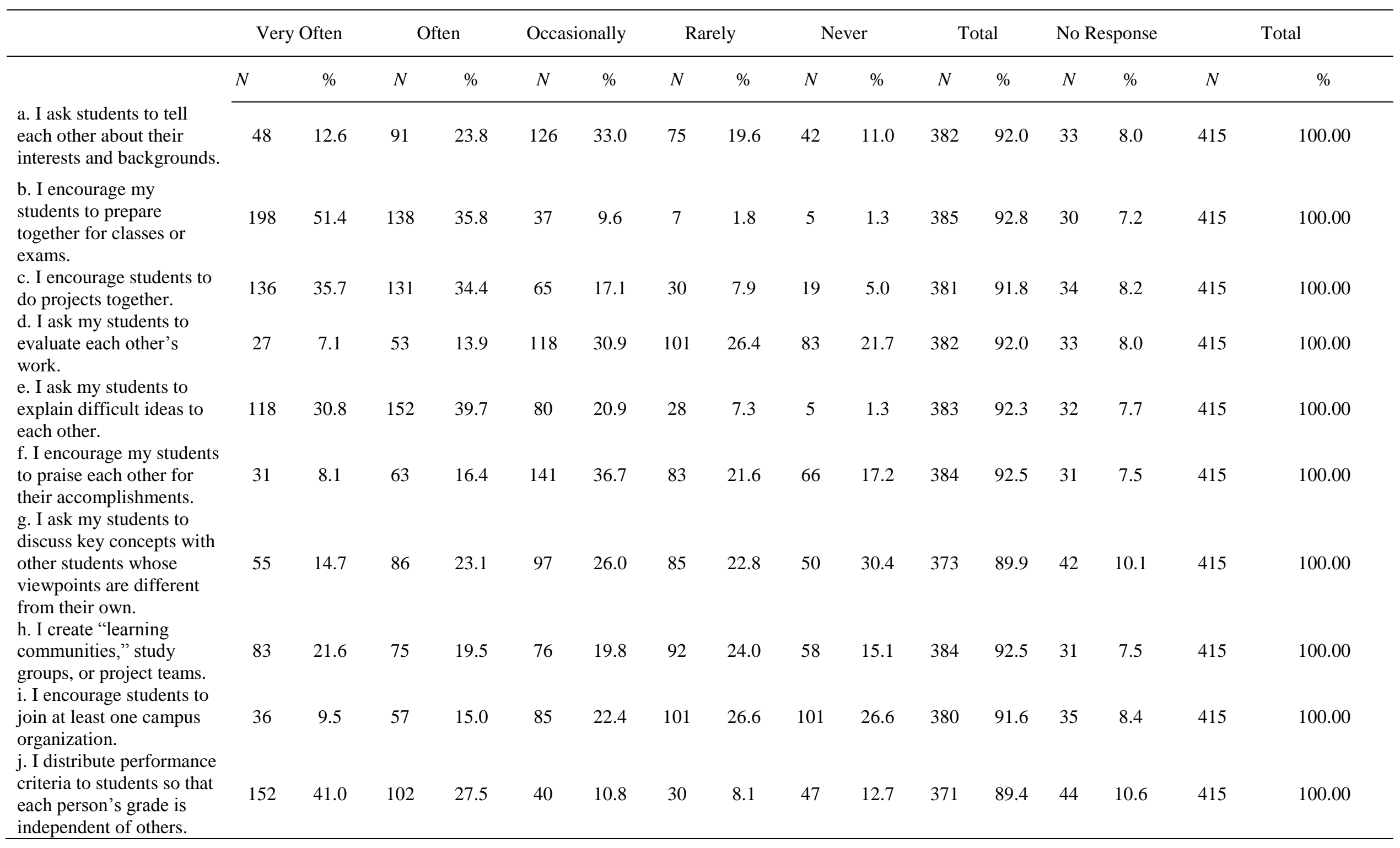


The third principle states, "Good practice encourages active learning." Nearly two-thirds $(64.8 \%)$ of respondents indicated that they very often used simulations, roleplaying, or labs in their classes. Thirty-six percent of faculty often asked their students to relate outside events or activities to course material and encouraged students to challenge the ideas of faculty, course materials, and other students. Almost forty percent often gave students concrete, real-life situations to analyze. More than two-thirds (36.5\%) of faculty occasionally asked students to present work to the class, while 30 percent occasionally asked students to undertake research and encouraged students to suggest course activities. Thirty-one percent of respondents rarely asked students to summarize similarities and differences among theorists and research findings. Nearly half of faculty never arranged field trips, volunteer activities, or internships (49.9\%) or carried out research projects with students $(48.2 \%)$ (see Table 11$)$. 
Table 11

Principle 3: Good Practice Encourages Active Learning

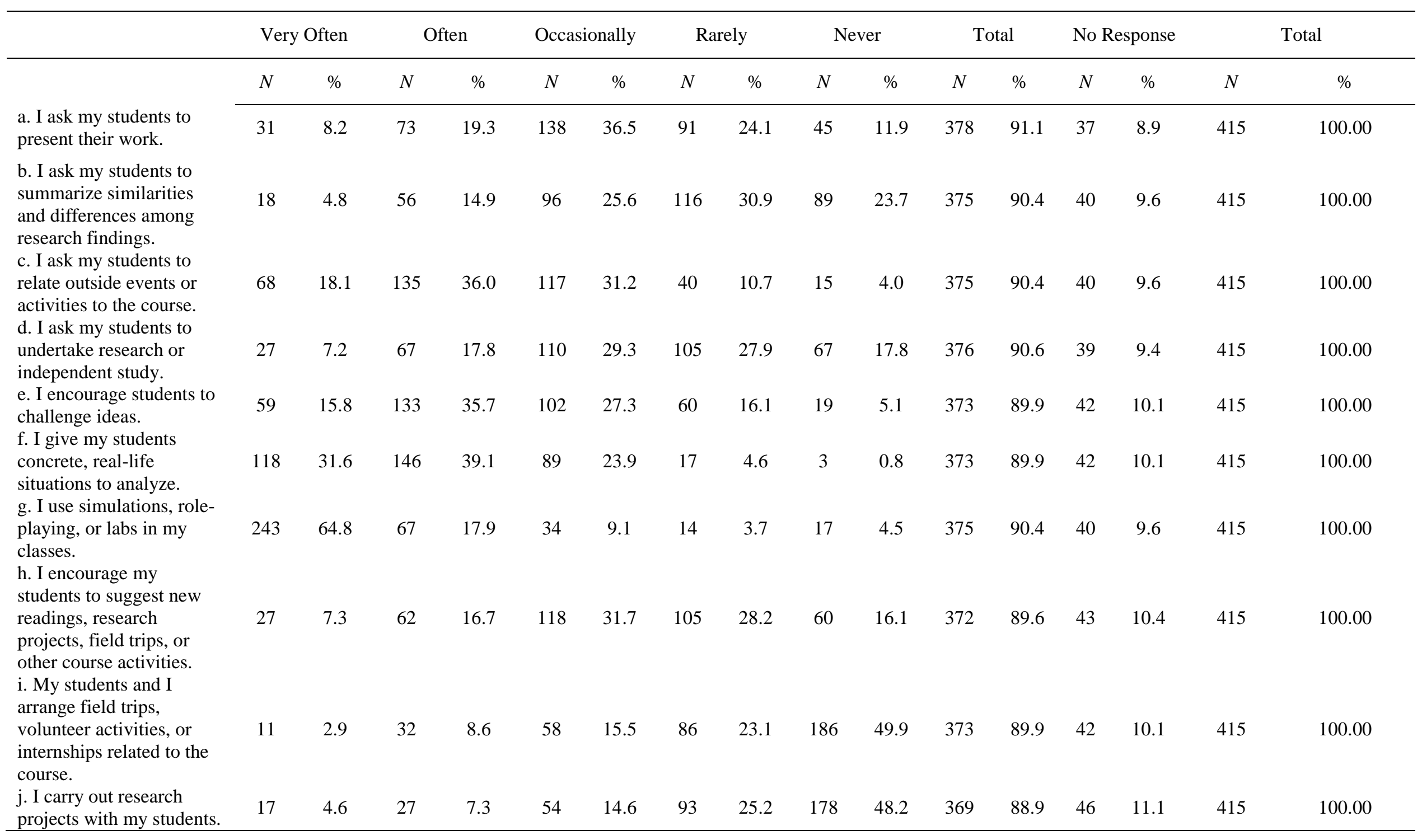


The fourth principle states, "Good practice gives prompt feedback." Eighty-five percent of respondents said they very often returned examinations and papers within a week, while nearly 80 percent (78.9\%) gave quizzes and homework assignments. Over two-thirds $(69.0 \%)$ of faculty indicated that they very often prepared classroom exercises and problems which give students immediate feedback on their progress. One-half of faculty very often gave students detailed evaluations of their work early in the term, and nearly one-third (30.5\%) very often gave students written comments on papers. Thirtyone percent of respondents occasionally asked students to schedule conferences to discuss progress, and the same percentage also occasionally called or wrote a note to students who miss classes. Almost 40 percent of faculty indicated that they never gave students pre-tests (39.8\%), asked students to keep logs or progress records $(42.1 \%)$, or discussed the results of the final exam with students (37.0\%) (see Table 12). 
Table 12

Principle 4: Good Practice Gives Prompt Feedback

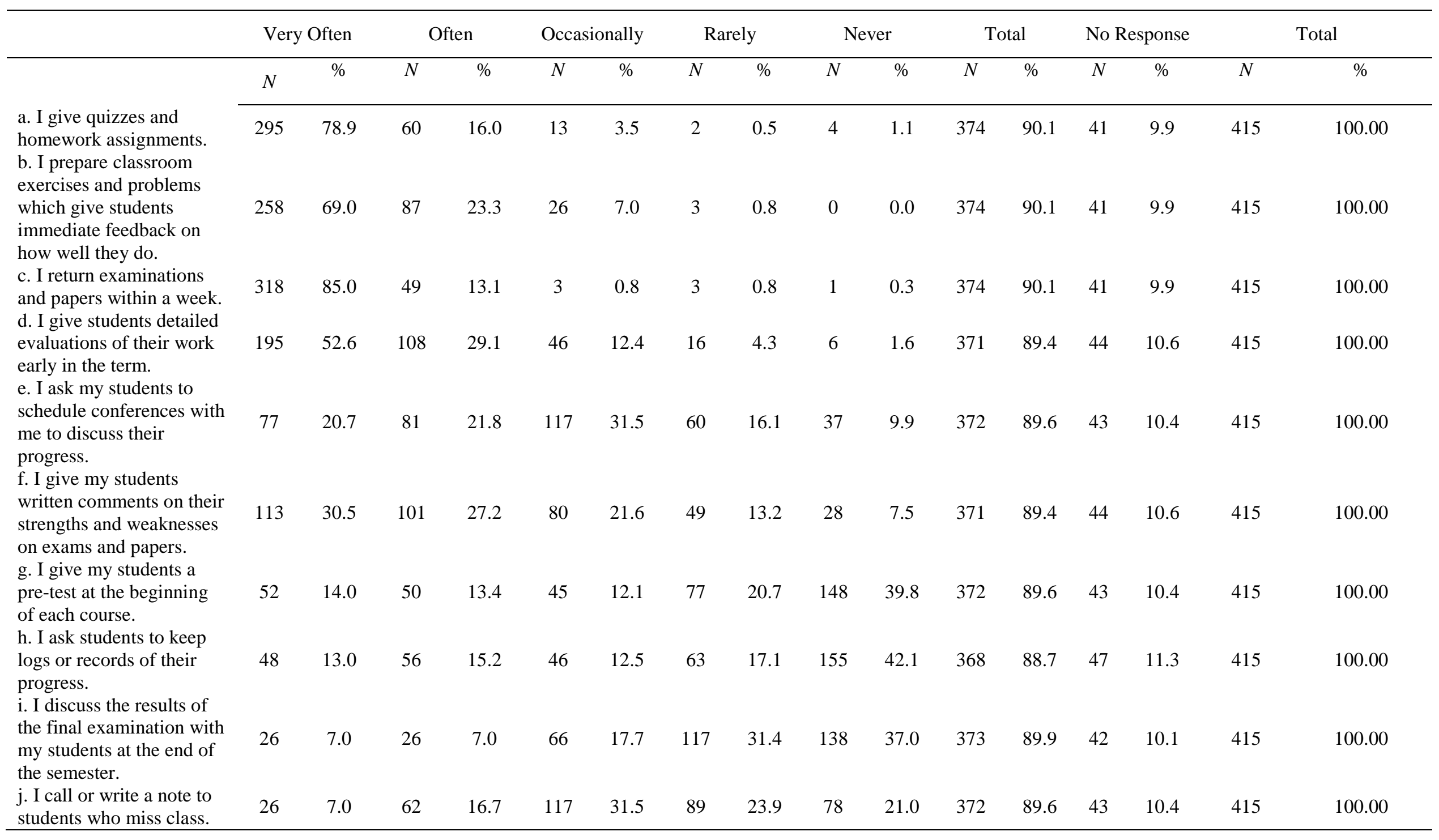


The fifth principle states, "Good practice emphasizes time on task." Nearly 80 percent $(78.6 \%)$ of faculty indicated that they very often expected students to complete assignments promptly. Sixty-seven percent of respondents very often underscored the importance of regular work, application, and scheduling, as well as explained the consequences of non-attendance. Over half (54.3\%) of participants very often communicated to students the minimum amount of time they should spend preparing for class, and nearly the same percentage of faculty $(56.2 \%)$ indicated they very often made clear to students the amount of time required to understand material. Forty-nine percent of respondents reported very often making clear that being a full-time student requires full-time work, and 39 percent very often required students to make up work when they miss class. More than one-third (34.2\%) of faculty often helped students set challenging goals for themselves, and 33 percent occasionally met with students who fall behind. Thirty percent of participants never encouraged students to rehearse for oral or class presentations (see Table 13). 
Table 13

Principle 5: Good Practice Emphasizes Time on Task

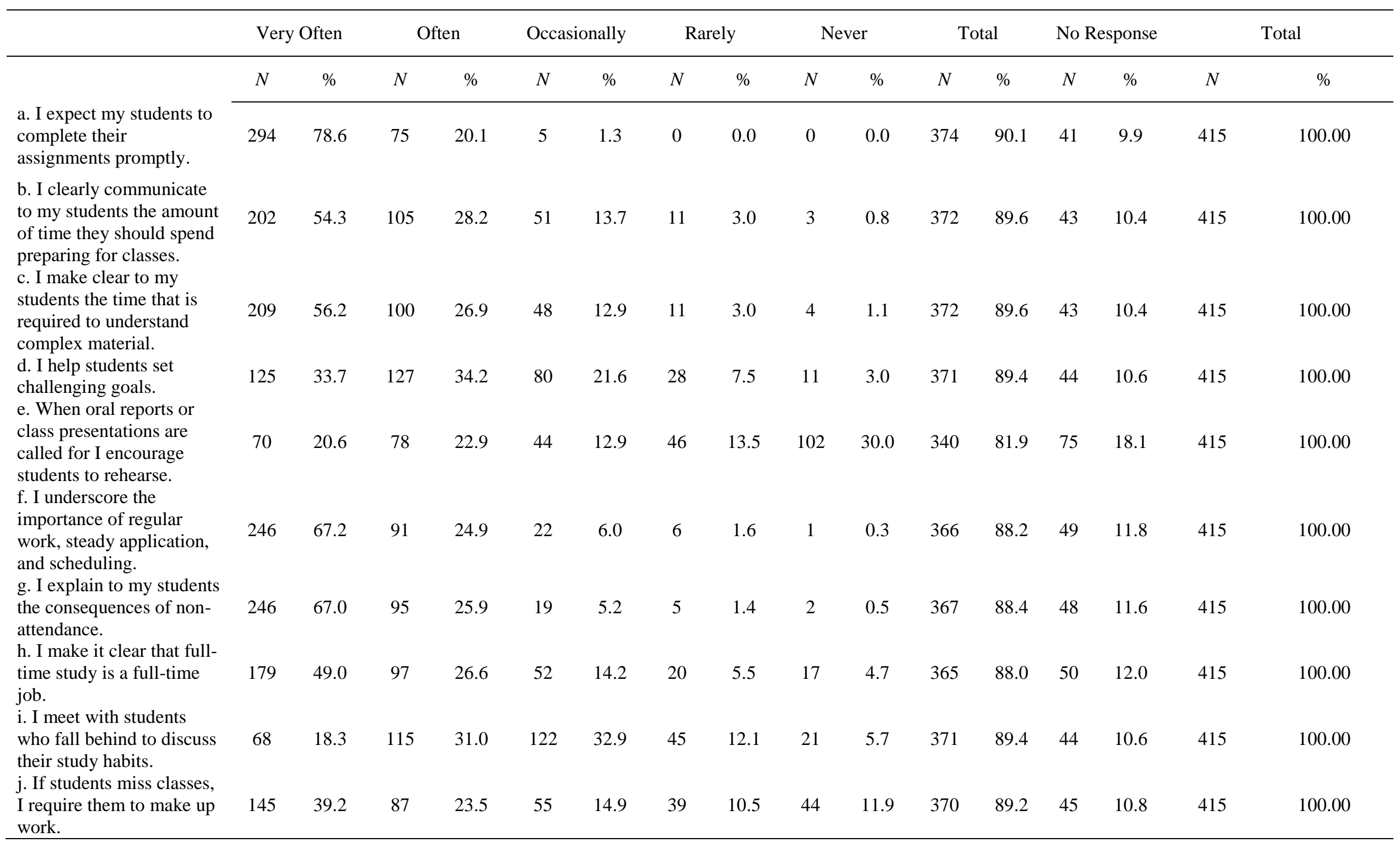


The sixth principle states, "Good practice communicates high expectations." Nearly eighty-five percent (84.4\%) of faculty reported very often making clear their expectations orally and in writing at the beginning of the course. Over two-thirds of respondents indicated they very often told students they expected them to work hard (71.2\%), emphasized the importance of high standards (68.7\%), and explained to students what will happen if work is not completed on time (66.9\%). Fifty-four percent of faculty very often revised their courses to include new information. More than one-third (34.9\%) of participants indicated they often helped students set goals for their learning, and 41 percent often discussed how well that class was doing during the course of the semester. Around 30 percent of respondents occasionally suggested extra reading or writing tasks (28.4\%), encouraged students to write a lot (33.1\%), and publicly called attention to excellent student performance (30.1\%) (see Table 14). 
Table 14

Principle 6: Good Practice Communicates High Expectations

\begin{tabular}{|c|c|c|c|c|c|c|c|c|c|c|c|c|c|c|c|c|}
\hline & \multicolumn{2}{|c|}{ Very Often } & \multicolumn{2}{|c|}{ Often } & \multicolumn{2}{|c|}{ Occasionally } & \multicolumn{2}{|c|}{ Rarely } & \multicolumn{2}{|c|}{ Never } & \multicolumn{2}{|c|}{ Total } & \multicolumn{2}{|c|}{ No Response } & \multicolumn{2}{|c|}{ Total } \\
\hline & $N$ & $\%$ & $N$ & $\%$ & $N$ & $\%$ & $N$ & $\%$ & $N$ & $\%$ & $N$ & $\%$ & $N$ & $\%$ & $N$ & $\%$ \\
\hline $\begin{array}{l}\text { a. I tell students that I } \\
\text { expect hard work. }\end{array}$ & 265 & 71.2 & 88 & 23.7 & 17 & 4.6 & 2 & 0.5 & 0 & 0.0 & 372 & 89.6 & 43 & 10.4 & 415 & 100.00 \\
\hline $\begin{array}{l}\text { importance of holding } \\
\text { high standards. }\end{array}$ & 255 & 68.7 & 86 & 23.2 & 26 & 7.0 & 3 & 0.8 & 1 & 0.3 & 371 & 89.4 & 44 & 10.6 & 415 & 100.00 \\
\hline $\begin{array}{l}\text { c. I make clear my } \\
\text { expectations orally and } \\
\text { in writing for each } \\
\text { course. }\end{array}$ & 314 & 84.4 & 50 & 13.4 & 6 & 1.6 & 1 & 0.3 & 1 & 0.3 & 372 & 89.6 & 43 & 10.4 & 415 & 100.00 \\
\hline $\begin{array}{l}\text { d. I help students set } \\
\text { challenging goals for } \\
\text { learning. }\end{array}$ & 120 & 33.0 & 127 & 34.9 & 81 & 22.3 & 22 & 6.0 & 14 & 3.8 & 364 & 87.7 & 51 & 12.3 & 415 & 100.00 \\
\hline $\begin{array}{l}\text { e. I explain to students } \\
\text { what will happen if } \\
\text { they do not complete } \\
\text { their work on time. }\end{array}$ & 249 & 66.9 & 95 & 25.5 & 21 & 5.6 & 5 & 1.3 & 2 & 0.5 & 372 & 89.6 & 43 & 10.4 & 415 & 100.00 \\
\hline $\begin{array}{l}\text { f. I suggest extra } \\
\text { reading or writing. }\end{array}$ & 102 & 27.6 & 85 & 23.0 & 105 & 28.4 & 44 & 11.9 & 34 & 9.2 & 370 & 89.2 & 45 & 10.8 & 415 & 100.00 \\
\hline $\begin{array}{l}\text { g. I encourage students } \\
\text { to write a lot. }\end{array}$ & 43 & 11.7 & 78 & 21.3 & 121 & 33.1 & 72 & 19.7 & 52 & 14.2 & 366 & 88.2 & 49 & 11.8 & 415 & 100.00 \\
\hline $\begin{array}{l}\text { h. I publicly call } \\
\text { attention to excellent } \\
\text { performance. }\end{array}$ & 48 & 13.1 & 83 & 22.7 & 110 & 30.1 & 65 & 17.8 & 60 & 16.4 & 366 & 88.2 & 49 & 11.8 & 415 & 100.00 \\
\hline i. I revise my courses. & 203 & 54.4 & 120 & 32.2 & 44 & 11.8 & 4 & 1.1 & 2 & 0.5 & 373 & 89.9 & 42 & 10.1 & 415 & 100.00 \\
\hline $\begin{array}{l}\text { j. I periodically discuss } \\
\text { how well we are doing. }\end{array}$ & 127 & 34.3 & 151 & 40.8 & 72 & 19.5 & 11 & 3.0 & 9 & 2.4 & 370 & 89.2 & 45 & 10.8 & 415 & 100.00 \\
\hline
\end{tabular}


The seventh and final principle states, "Good practice respects diverse talents and ways of learning." More than 80 percent $(83.0 \%)$ of respondents indicated they very often encouraged students to speak up when they did not understand. Over half $(55.2 \%)$ of faculty reported very often discouraging stride remarks, sarcasm, and other class behaviors that may embarrass students, and 45 percent very often used diverse teaching activities to address a broad spectrum of students. More than 30 percent very often provided extra material or exercises for students who lacked background knowledge or skills $(32.1 \%)$ and tried to find out about student learning styles, interests, or backgrounds $(30.7 \%)$. One-third (32.8\%) of faculty members reported occasionally integrating new knowledge about women and minorities, and less than one-third (26.7\%) occasionally selected reading and designed activities related to the background of students. Nearly half $(46.3 \%)$ of participants never encouraged students to design their own majors. Thirty-three percent of faculty reported never making explicit provisions for students who wish to carry out independent studies, and nearly as many (29.3\%) reported never developing mastery learning, learning contracts, or computer assisted learning alternatives (see Table 15). 
Table 15

Principle 7: Good Practice Respects Diverse Talents and Ways of Learning

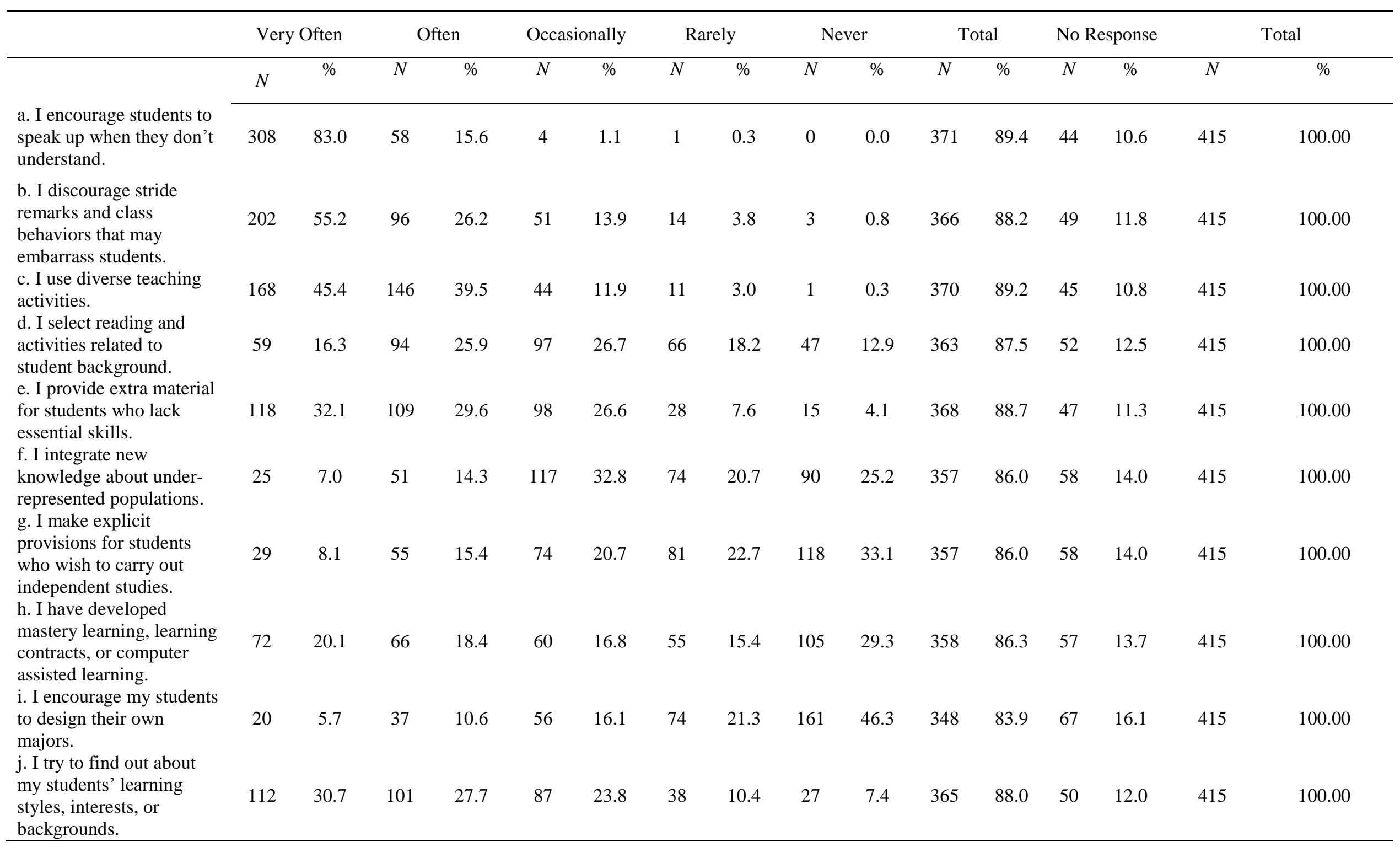




\section{Research Question 2}

The second research question examined significant differences in principle utilization by type of principle. To compare the seven principles, each set of ten survey items per principle was summed for each individual. This provided a "total score" with a range of 10 to 50 for each principle. For example, a score of 50 suggests that an individual faculty member very often performed all ten actions in regard to a specific principle. By contrast, a score of 10 suggests an individual faculty member never performed those ten actions in regard to a specific principle. Means and standard deviations of the total scores for each principle were determined, and $t$-tests were computed to explore differences among the seven principles. The values for these $t$-tests are presented in Table 16. Statistical significance findings are indicated at the $p<.05$ and $p<.01$ levels. Accordingly, 21 comparisons are shown in Table 16.

Significant differences in the frequency of use between the seven principles were found (see Table 16). Some principles are more often used than others. For example, faculty rated principles five and six (time on task and high expectations) with significantly higher mean total scores (mean total scores 40.63 and 40.42, respectively) than the other five principles. Faculty least used (mean total score $=29.87, \mathrm{SD}=6.52$ ) active learning (principle three) as compared to the other six principles. 


\section{Table 16}

Comparison of Principle Utilization by Type of Principle

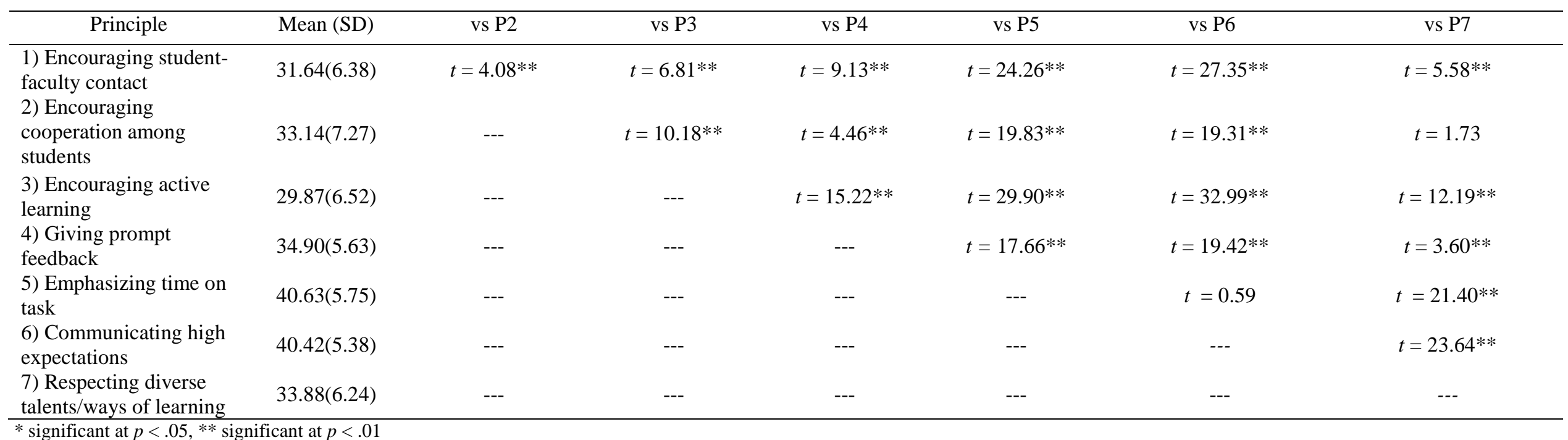

* significant at $p<.05, * *$ significant at $p<.01$ 


\section{Research Question 3}

The third research question examined significant differences in utilization of principles by accreditation region. Four of the six accreditation regions were used in this study: Middle States, New England, North Central, and Southern. First, an overall MANOVA was computed in which the independent variable was accreditation regions, and the dependent variables were the mean total scores for the seven principles. This first analysis (MANOVA), if it yielded an overall statistically significant difference (at least $p$ $<.05$ ) would allow seven subsequent analyses of variance (ANOVAs) without compromising Type I error. This MANOVA produced a significant overall finding $F(7)$ $=997.23, p<.01$, and thus warranted additional ANOVAs.

As may be noted in Table 17, only the ANOVA across the four regions for principle 2 yielded a significant difference, $\mathrm{F}(3 / 262)=3.00$, $\mathrm{p}<.05$, and no other significant differences were found. When the Tukey multiple comparison follow-up test was computed, it indicated a strong trend $(p=.08)$ between the New England and North Central accreditation regions. 
Table 17

Principle Utilization by Accreditation Region

\begin{tabular}{lcc}
\hline \multicolumn{1}{c}{ Principle } & df & F \\
\hline $\begin{array}{l}\text { 1) Encouraging student- } \\
\text { faculty contact }\end{array}$ & $3 / 262$ & 1.08 \\
$\begin{array}{l}\text { 2) Encouraging } \\
\text { cooperation among } \\
\text { students }\end{array}$ & $3 / 262$ & $3.00 *$ \\
$\begin{array}{l}\text { 3) Encouraging active } \\
\text { learning }\end{array}$ & $3 / 262$ & 1.57 \\
$\begin{array}{l}\text { 4) Giving prompt } \\
\text { feedback } \\
\begin{array}{l}\text { 5) Emphasizing time on } \\
\text { task }\end{array}\end{array}$ & \\
$\begin{array}{l}\text { 6) Communicating high } \\
\text { expectations } \\
\text { 7) Respecting diverse } \\
\text { talents/ways of learning }\end{array}$ & $3 / 262$ & 0.21 \\
*significant at $p<.05$ & $3 / 262$ & 0.13 \\
\end{tabular}

*significant at $p<.05$

Research Question 4

Research question four looked for significant differences in utilization of principles by gender of instructor. Once again, the total mean scores were the dependent variable, and gender was the independent variable. A MANOVA for gender by the seven principles yielded $\mathrm{F}(7 / 268)=2745.69, p<.01$, indicating that further ANOVAs would be appropriate. In these additional ANOVAs, a significant difference was discovered between male faculty members and female faculty members in utilization of principles two (cooperation among students, $p<.05$ ), four (prompt feedback, $p<.05$ ), and five (time on task, $p<.05)$. There was a strong trend $(p=.055)$ for principle six (high expectations). For all three of these statistically significant principles, as well as the 
trend, the mean total score for female faculty was higher than the mean total score for male faculty (see Table 18). 
Table 18

Comparison of Utilization of Principles by Gender

\begin{tabular}{|c|c|c|c|c|c|c|}
\hline Principle & $\begin{array}{c}\text { Mean Score for } \\
\text { Males }\end{array}$ & SD & $\begin{array}{c}\text { Mean Score for } \\
\text { Females }\end{array}$ & SD & $\mathrm{df}$ & $\mathrm{F}$ \\
\hline $\begin{array}{l}\text { 1) Encouraging } \\
\text { student-faculty } \\
\text { contact }\end{array}$ & 31.68 & 6.38 & 32.33 & 6.45 & $1 / 274$ & 0.67 \\
\hline $\begin{array}{l}\text { 2) Encouraging } \\
\text { cooperation among } \\
\text { students }\end{array}$ & 32.74 & 6.82 & 34.69 & 7.18 & $1 / 274$ & $5.03 *$ \\
\hline $\begin{array}{l}\text { 3) Encouraging active } \\
\text { learning }\end{array}$ & 29.84 & 6.30 & 30.16 & 6.87 & $1 / 274$ & 0.15 \\
\hline $\begin{array}{l}\text { 4) Giving prompt } \\
\text { feedback }\end{array}$ & 34.48 & 5.62 & 36.08 & 5.19 & $1 / 274$ & $5.51 *$ \\
\hline $\begin{array}{l}\text { 5) Emphasizing time } \\
\text { on task }\end{array}$ & 40.20 & 5.90 & 41.75 & 4.83 & $1 / 274$ & $5.12 *$ \\
\hline $\begin{array}{l}\text { 6) Communicating } \\
\text { high expectations }\end{array}$ & 40.15 & 5.34 & 41.39 & 4.87 & $1 / 274$ & 3.72 \\
\hline $\begin{array}{l}\text { 7) Respecting diverse } \\
\text { talents/ways of } \\
\text { learning }\end{array}$ & 33.76 & 6.10 & 34.39 & 6.36 & $1 / 274$ & 0.66 \\
\hline
\end{tabular}

* significant at $p<.05$ 


\section{Research Question 5}

Research question five examined differences in principle utilization by class size.

For this study, class size was defined as small (1 to 20 students), medium (20 to 40

students), or large (41 or more students). Total mean scores were the dependent variable, and class size was the independent variable. A MANOVA for class size by the seven principles showed $\mathrm{F}(7 / 268)=1469.07, p<.01$, indicating that further ANOVAs would be appropriate. In these additional ANOVAs, no statistically significant differences were found (see Table 19).

Table 19

Principle Utilization by Class Size

\begin{tabular}{lcc}
\hline \multicolumn{1}{c}{ Principle } & DF & F \\
\hline $\begin{array}{l}\text { 1) Encouraging student- } \\
\text { faculty contact }\end{array}$ & $2 / 274$ & 0.06 \\
$\begin{array}{l}\text { 2) Encouraging } \\
\text { cooperation among } \\
\text { students }\end{array}$ & $2 / 274$ & 2.82 \\
$\begin{array}{l}\text { 3) Encouraging active } \\
\text { learning }\end{array}$ & $2 / 274$ & \\
$\begin{array}{l}\text { 4) Giving prompt } \\
\text { feedback }\end{array}$ & $2 / 274$ & 0.25 \\
$\begin{array}{l}\text { 5) Emphasizing time on } \\
\text { task } \\
\text { 6) Communicating high } \\
\text { expectations }\end{array}$ & $2 / 274$ & 0.01 \\
7) Respecting diverse \\
talents/ways of learning
\end{tabular}

In summary, the demographic information gleaned from survey results characterized the respondents as mostly male faculty members (62.7\%) who mainly teach 
full-time at one institution (77.8\%). The general class size for respondents of this survey was medium, indicating that most faculty members $(65.8 \%)$ had a typical class size of 21 to 40 students. Fifty-six percent of the respondents were veteran instructors with more than 10 years of experience in higher education. More than one-half $(53.5 \%)$ of respondents obtained a doctorate in their field, and nearly one-half (43.6\%) of respondents obtained a master's degree.

Faculty responded that they indeed used the seven principles to different extents. For example, it was evident that faculty often communicated high expectations (principle 6 , mean total score $=40.42, \mathrm{SD}=5.38)$ ) and emphasized time on task (principle 5 , mean total score $=40.63, \mathrm{SD}=5.75)$. However, they encouraged active learning with far less frequency (principle 3 , mean total score $=29.87, \mathrm{SD}=6.52$ ). No significant differences were found in principle utilization by accreditation region or class size, but a significant difference was found in principle utilization by gender of instructor. Female faculty members indicated that they used principles two (cooperation among students), four (prompt feedback), and five (time on task) more often than male faculty members. 


\section{CHAPTER 5}

\section{Conclusions and Recommendations}

The previous chapters examined the background research on and utilization of the Seven Principles of Good Practice in Undergraduate Education (Gamson, 1991). The study focused on the utilization of these principles by community college chemistry instructors, a population with little representation in literature. The purpose of the study was to examine differences in principle utilization by principle, accreditation region, gender, and class size.

\section{Conclusions}

The total number of returned surveys was 415 out of 2349 e-mail invitations sent for a $17.7 \%$ response rate. The lower than expected response rate was likely due to the length of the survey, which included 10 demographics questions and 70 survey questions. Most respondents were male (62.7\%) and taught full-time at one institution (77.8\%). It was difficult to obtain contact information for adjunct faculty, as their positions changed frequently. Changing positions could contribute to the low response rate $(19.8 \%)$ from part-time faculty members. Most respondents were from the Southern Association of Colleges and Schools (38.8\%) and the North Central Association of Colleges and Schools (32.8\%), with the fewest (4.1\%) from the New England Association of Schools and Colleges. These results make sense in terms of New England's response rate because there were the fewest faculty contacts (92 e-mail addresses collected) in that region. However, the most contacts (921 e-mail addresses collected) were from the North Central region, with the Southern region containing 852 contacts. 
Principle one focused on student-faculty contact, and as expected, faculty reported they often knew student names, advised students, and encouraged office visits. Faculty less often worked with students outside the classroom, indicating they rarely worked with student affairs staff, took students to professional meetings, or participated in resolution of conflict on campus. This particular result makes sense in terms of time constraints imposed on faculty members at any institution.

Chemistry instructors who participated in this survey reported fostering cooperation among students (principle 2) by encouraging students to work together on projects, test preparation, and class work. Faculty reported rarely using learning communities, campus organizations, and peer evaluations. Typically, community they seemed to encourage students working together for the benefit of the course, but were not as proactive in encouraging student cooperation in the wider arena of the institution.

Principle three focused on active learning and faculty responded that they often gave students real-life situations to analyze, provided labs and simulations, and encouraged students to challenge and analyze ideas. However, faculty indicated that they did not often carry out research projects with students, which makes sense considering community colleges tend to provide basic courses and not research-based courses. Faculty also indicated that they did not arrange field trips, volunteer activities, or internships related to chemistry; this is understandable considering the subject matter. The study of chemistry does not have many applicable field trips until the more specialized courses such as physical chemistry or biochemistry.

Principle four focused on prompt feedback as a manner of good practice. Faculty indicated that they often gave quizzes, homework assignments, and classroom exercises 
to provide feedback on student comprehension. Faculty also indicated that they often returned examinations within a week and provided detailed evaluations of their work through written comments and office visits. Faculty in this study typically did not give pre-tests at the beginning of the course, nor did they ask students to keep logs or records of their progress. If faculty members more often utilized these types of actions, the community college students could learn to become self-reliant learners prepared for further education. Faculty also indicated that they did not discuss the results of the final examination with the students; however, considering the final exam is typically the last day of class, there is little opportunity to interact with students on this matter.

Faculty indicated they often utilized many aspects of principle five, emphasizing time on task. According to their responses, faculty often expect students to turn in work promptly, communicate expectations and the importance of regular time set aside for study, and explain consequences of missing class time. However, faculty tended not to assign oral reports for general chemistry courses since these courses are introductions to chemistry.

Principle six focused on communicating high expectations. Faculty indicated that they often informed students (both orally and in writing) that they expected them to work hard and emphasized the importance of high standards for academic achievement. Faculty also often explained to students what will happen if work is not completed on time and they revised courses to accommodate new information. Faculty responded that they did not frequently suggest extra reading or writing or encourage students to write a lot. The study of general chemistry involves substantial problem solving and calculations, which does not require lengthy writing or reading research. Faculty also 
indicated that they did not often publicly call attention to excellent performance by students, which could be due to privacy issues.

Principle seven focused on respecting diverse talents and ways of learning. Faculty who responded indicated they often encouraged students to speak up when they did not understand, discouraged disparaging remarks, and tried to discern student learning styles, interests, and backgrounds. Faculty also indicated that they often used diverse teaching activities and provided extra material or exercises for students who needed help with skills. However, faculty indicated that they rarely made provisions for students to carry out independent studies or design their own major. General chemistry courses are introductory courses not suited to independent study, and the community college is not designed to create majors for students to pursue. Also, faculty indicated that they did not often develop mastery learning, learning contracts, or computer assisted learning alternatives.

Upon comparison of principle utilization in response to the second research question, it became apparent that each principle was used to a different extent. The principles were compared by totaling responses for the ten questions per principle, allowing a total score of 10 to 50 per respondent. The respondents' scores were evaluated to provide the mean and standard deviation for total scores for each principle. Most of the principles' mean total scores were significantly different from one another. The most-used principles were principles five and six (emphasizing time on task and communicating high expectations, respectively), each with a mean total score of more than 40. According to Bracey (2001), students are more engaged, and therefore spend more time on task, in courses that are academically challenging such as science and 
mathematics. The relatively high mean score for principle five (emphasizing time on task, mean total score $=40.63, \mathrm{SD}=5.75$ ) could be due not only to instructor time on task, but also the student focus necessary to comprehend the subject. The high mean score for principle six (communicating high expectations, mean total score $=40.42, \mathrm{SD}=$ 5.38) indicated that faculty believed they were communicating the need to work hard and put appropriate amounts of time into study. However, research implies that faculty expectations are rarely clearly defined (Barrowman, 1996). More specifically, expectations are not explicitly defined and contextualized to apply to the course in question (Barrowman, 1996, p. 108). The analysis of this principle would benefit from in-depth study of syllabi and observation of faculty to determine how expectations are defined. The least-used principle was principle three (mean total score $29.87, \mathrm{SD}=$ 6.52), encouraging active learning. This result could be due to the difficulty of utilizing active learning in a fact-based course such as chemistry, which leaves little room for opinion or creative thinking on the general level (Zoller, 1999). Another possible issue contributing to active learning as least-utilized principle is that faculty are often concerned that less material is covered in an active learning environment (O'Sullivan \& Copper, 2003).

In response to the third research question regarding utilization of principles by accreditation region, there was no significant difference found between regions. The fourth research question examined utilization of principles by gender of instructor, and a significant difference was found in principles two (encouraging cooperation among students), four (giving prompt feedback), and five (emphasizing time on task). According to the ANOVAs calculated for this research question, female faculty members 
responded with higher mean total scores than male faculty members for these three principles. This result is consistent with findings in educational research that imply "women were more likely to hold a conception of teaching as learning facilitation, whereas men were more likely to hold a conception of teaching as knowledge transmission" (Norton et. al., 2005, p. 559). The fifth and final research question examined differences in principle utilization by class size. No significant differences were found in this comparison.

\section{Recommendations}

Based on the results of this study, recommendations can be made for improving chemistry education at two-year colleges. The first set of recommendations focuses on practical implementations community college instructors can utilize in practice, and the second set of recommendations suggests future areas of research in this area.

Recommendations for Practice

The first recommendation for practice is that faculty may want to reconsider their participation in campus life. Faculty participation in campus life or student affairs is an area of good practice that could be improved upon by instructors. Throughout all seven principles, respondents consistently reported that they occasionally or rarely participated or encouraged student participation in campus activities. One of the difficult areas of community college education is the transient nature of students. Results from the 2008 Community College Survey of Student Engagement (CCSSE) found low participation rates for programs designed to enhance engagement, such as learning communities and courses designed to help with study skills and time management. Students went to campus only to go to class (Marklein, 2008). The study recognized that if student 
engagement were to be improved, an environment that enabled success and support would need to be cultivated. If instructors participated or encouraged participation, students may feel more involved and more committed to campus life.

The second recommendation is that chemistry faculty reconsider how they assess student learning. For example, chemistry faculty could devise a pre-test for students to take at the beginning of the course to gauge previous subject knowledge. Analysis of the pre-test could help faculty narrow the focus of what information needed covered in the course, perhaps allowing more time for activities or projects relevant to chemistry education. Other survey items, such as carrying out projects with students or arranging field trips for students, would not mesh well with the community college environment. Since community college students do not typically reside on campus and often work besides attending college, it is not realistic to expect students to complete a lot of campus-based extracurricular work.

The third recommendation is for administration and department chairs to survey their students and faculty using Chickering and Gamson's inventory (1991) to determine needs in the department. The faculty inventory of the seven principles would be helpful for department chairs to identify areas for future faculty development sessions, and should include both full-time and adjunct faculty. It could be used to facilitate discussion about areas that could improved upon and what changes are realistic to make. Not all areas of the inventory are realistic for two-year colleges or for chemistry. Braxton, Olsen, and Simmons (1998) found that the seven principles are not likely to be utilized in high paradigmatic disciplines such as chemistry. By using the faculty inventory, dialogue could begin and improvements could be suggested by faculty members. 


\section{Recommendations for Research}

The first recommendation for future research is to perform a case study on how science faculty use the seven principles in practice. By observing faculty members in and outside of the classroom, much information could be gleaned on the challenges and benefits of implementing the principles. According to Suskie (1996), a limitation of Likert scale survey responses is that it is self-reporting data, which may not be as accurate as an observation. Survey data is generic in nature, but data gathered by observation and discussion would provide richer analyses of the seven principles. Likert data also can create the "yeasayer/naysayer effect," in which the attitude of the respondent affects responses for the entire survey (Suskie, 1996, p. 34). For example, a respondent who is generally negative about educational research may simply respond "rarely" or "never" without reading the survey. On the other hand, a respondent who is generally positive about the research topic may fill in "very often" without truly reading the survey (Suskie, 1996, p. 34).

The second recommendation for research is to expand the population of the study regarding the seven principles. One option is to include four-year and graduate chemistry faculty. Perhaps some of the differences found in principle utilization were due to the type of institution studied; however, this connection cannot be made unless compared to other types of institutions. Including other areas of science, such as physics and biology, could also provide an expanded population and new results. While research indicates that sciences are less likely than other subjects to utilize the seven principles (Braxton, Olsen, \& Simmons, 1998), an in-depth analysis of how different sciences use the principles could be valuable. Further expanding the population by including administrators in the 
survey would help delineate expectations from leadership and realities from instructors. For example, administrators may believe their faculty are utilizing active learning to a great extent, but faculty may indicate that it is difficult or impossible in certain areas.

Finally, the third recommendation for research is to analyze free-response questions regarding the seven principles. This analysis could provide insight into how faculty value each of the principles. Allowing for candid responses regarding each principle could provide rich information for future explorations of the principles. As mentioned earlier, Likert scale responses have limitations for analysis, but free responses would allow faculty to express how they are implementing principles and what they feel is realistic and beneficial to explore in the future.

\section{Summary}

This study provided information on how community college chemistry instructors utilize the Chickering and Gamson's Seven Principles of Good Practice in Undergraduate Education (1991). It examined background information regarding each of the principles and reviewed the research plan designed to examine principle utilization through a survey. Results from the survey showed that there is a difference in principle utilization by type of principle. All instructors could benefit from self-examination using the seven principles. 


\section{References}

Barr, R. \& Tagg, J. (1995). From teaching to learning - a new paradigm for undergraduate education. Change, 27(6), 12-26.

Barrowman, C.E. (1996). Improving teaching and learning effectiveness by defining expectations. New Directions for Higher Education. 24(4), 103-114.

Bent, H.A. (1961).Why lecture? In International Symposium on University Chemical Education (pp. 16-17). Frascati, Italy.

Bonwell, C.C. \& Eison, J.A. (1991). Active learning: Creating excitement in the classroom. ASHE-ERIC Higher Education Report No.1. Washington, DC: The George Washington University, School of Education and Human Development.

Bracey, G.W. (2001). At the beep, pay attention. Phi Delta Kappan, 82(7), 555-556.

The Carnegie Foundation for the Advancement of Teaching (2007). Classification listing. Retrieved December 4, 2007 from http://www.carnegiefoundation.org

Chickering, A. \& Ehrmann, S.C. (1996). Implementing the Seven Principles: Technology as lever. Retrieved May 7, 2005 from http://www.tltgroup.org/programs/ seven.html

Deden, A. \& Carter, V.K. (1996). Using technology to enhance students' skills. In E.A. Jones (Ed.), Preparing competent college graduates: Setting new and higher expectations for student learning (pp. 81-92). San Francisco: Jossey-Bass, Inc.

Drysdale, M.T.B, Ross, J.L., \& Schulz, R.A. (2001). Cognitive learning styles and academic performance in 19 first-year university courses: Successful students versus students at risk. Journal of Education for Students Placed at Risk, 6(3), 271-289. 
Dunn, R. \& Dunn, K. (1978). Teaching students through their individual learning styles: A practical approach. Reston, VA: Reston Publishing Company.

Flaherty, G. (1992). The learning curve: Why textbook teaching doesn't work for all kids. Vocational Education Journal, 67(6), 32-33, 56.

Gamson, Z.F. (1991). A brief history of the Seven Principles for Good Practice in Undergraduate Education. In A.W. Chickering \& Z.F. Gamson (Eds.), Applying the Seven Principles for Good Practice in Undergraduate Education (pp. 5-12). San Francisco: Jossey-Bass, Inc.

Gregorc, A. (1984). Style as a symptom: A phenomenological perspective. Theory Into Practice, 23(1), 51-56.

Gregorc, A. (1985). Inside styles: Beyond the basics. Maynard, MA: Gabriel Systems. Guild, P.B., and S. Garger. (1998). Marching to Different Drummers, 2nd edition. Alexandria: Association for Supervision and Curriculum Development.

Huba, M.E. \& Freed, J.E. (2000). Learner-centered assessment on college campuses: Shifting the focus from teaching to learning. Needham Heights, MA: Allyn \& Bacon.

Johnson, D.W., Johnson, R., \& Smith, K. (2006). Active learning: Cooperation in the college classroom. Edina, MN: Interaction Book Company.

Jones, E.A. (2002). Transforming the curriculum: Preparing students for a changing world. ASHE-ERIC Higher Education Report, 29(3).

Jones, J.W. \& Duffy, D.K. (1991). Activating learning in the classroom: Challenge, collaborate, celebrate. Middlesex Community College: Bedford, MA. 
Kadel, S. \& Keehner, J.A. (1994). Collaborative learning: A sourcebook for higher education, volume II. National Center on Postsecondary Teaching, Learning, and Assessment.

Kempa, R.F. \& Ayob, A. (1991). Learning interactions in group work in science. The International Journal of Science Education, 13(3), 341-354.

Light, R.J. (2001). Making the most of college: Students speak their minds. Cambridge: Harvard University Press.

Manner, B.M. (2001). Learning styles and multiple intelligences in students: Getting the most out of your students' learning. Journal of College Science Teaching, (30)6, 390-393.

Maitland Schilling, K. \& Schilling, K.L. (1999). Increasing expectations for student effort. About Campus, 4(2), 4-10.

Marklein, M.B. (2008). Engaging minds at community colleges. Retrieved April 7, 2010 from http://www.usatoday.com/news/education/2008-11-16-CCSSE_N.htm

Metzker, B. (2003). Time and learning (Digest No. 166). Oregon: ERIC Digests.

Michaelsen, L.K. (1998). Three keys to using learning groups effectively. Essays on Teaching Excellence, 9(5).

Middendorf, J. \& Kalish, A. (1996). The "Change-Up” in lectures. Forum, 5(2), 1-4.

Milshtein, A. (2003). Accommodating students' learning styles. College Planning \& Management, 6(3), 30-32.

Moran, S., Kornhaber, M., \& Gardner, H. (2006). Orchestrating multiple intelligences. Educational Leadership, 64(1), 22-27.

Myers, S.S. (1990). The management of curriculum time as it relates to student engaged 
time. Educational Review, 42(1), 13-24.

Neumann, Y. \& Finaly-Neumann, E. (1989). Examinations of alternative models of students' assessment of their college: Differences between hard and soft sciences. Assessment and Evaluation in Higher Education, 14(1), 11-19.

Newlin, M.H. \& Wang, A.Y. (2002). Integrating technology and pedagogy: Web instruction and Seven Principles of Undergraduate Education. Teaching of Psychology, 29(4), 325-330.

Norton, L., Richardson, J.T.E., Hartley, J., Newstead, S. \& Mayes, J. (2005). Teachers’ beliefs and intentions concerning teaching in higher education. Higher Education, $50(4), 537-571$.

O’Sullivan, D.W. \& Copper, C.L. (2003). Evaluating active learning: A new initiative for a general chemistry curriculum. Journal of College Science Teaching, 32(7), 448-452.

Page, D. \& Mukherjee, A. (2000). Improving undergraduate student involvement in Management Science and Business Writing courses using the Seven Principles in action. Education, 120(3), 547-559.

Pascarella, E.T. (1980). Student faculty informal contact and college outcomes. Review of Educational Research, 50, 545-595.

Penberthy, D.L. \& Millar, S.B. (2002). The "Hand-off" as a flawed approach to disseminating innovation: Lessons from chemistry. Innovative Higher Education, 26(4), 251-270.

Piburn, M.D., Reynolds, S.J., McAuliffe, C., Leedy, D.E., Birk, J.P., and Johnson, J.K. (2005). The role of visualization in learning from computer-based images. 
International Journal of Science Education, 27(5), 213-527.

Pierce, J.W. \& Jones, B.F. (1998). Problem-based learning: Learning and teaching in the context of problems. In Contextual teaching and learning: Preparing teachers to enhance student success in the workplace and beyond (ERIC Publication No. ED427263). Washington, DC: Office of Educational Research and Improvement.

Reid, N. \& Yang, M. (2002). The solving of problems in Chemistry: The more openended problems. Research in Science \& Technological Education, 20(1), 83-96.

Ritter, M.E. \& Lemke, K.A. (2000). Addressing the "Seven Principles for Good Practice in Undergraduate Education” with Internet-enhanced education. Journal of Geography in Higher Education, 24(1), 100-109.

Rochford, R.A. (2003). Assessing learning styles to improve the quality of performance of community college students in developmental writing programs: A pilot study. Community College Journal of Research and Practice, 27, 665-677.

Rouseff-Baker, F. \& Holm, A. (2004). Engaging faculty and students in classroom assessment of learning. New Directions for Community Colleges, 126, 29-42.

Schroeder, H. \& Ebert, D.G. (1983). Debates as business and society teaching technique. Journal of Business Education, 58(7), 266-269.

Shulman, L.S. (2007). Counting and recounting: Assessment and the quest for accountability. Change, 39(1), 20-25.

Sorcinelli, M.D. (1991). Research findings on the Seven Principles. In A.W. Chickering \& Z.F. Gamson (Eds.), Applying the Seven Principles for Good Practice in Undergraduate Education (pp. 13-25). San Francisco: Jossey-Bass, Inc. 
Suskie, L.A. (1996). Questionnaire survey research: What works, $2^{\text {nd }}$ ed. Tallahassee: Association for Institutional Research.

Teaching tips: Using the "Seven Principles of Good Undergraduate Education" to increase student centered learning. (2003). Journal of Student Centered Learning, 1(2), 105-110.

Tendy, S.M. \& Geiser, W.F. (1997). The search for style: It all depends on where you look. (Available from the ERIC Document Reproduction Service No. ED 410 029).

Tippett, C. (2003). Demonstrating understanding in science: Connections to learning styles. Canadian Children, 1, 21-28.

Umbach, P.D. \& Porter, S.R. (2002). How do academic departments impact student satisfaction? Understanding the contextual effects of departments. Research in Higher Education, 43(2), 209-234.

Uzuntiryaki, E., Bilgin, I., \& Geban, O. (2003). The effect of learning styles on high school students' achievement and attitudes in chemistry. Paper presented at the Annual Meeting of the National Association for Research in Science Teaching, Philadelphia, PA.

Van Der Karr, C.A. (1994). Lessons learned from study groups: Collaboration, cooperation, and involvement among community college students. Paper presented at the Annual Meeting of the Association for the Study of Higher Education, Tucson, AZ. 
Volkwein, J.F. \& Cabrera, A.F. (1998, May). Student measures associated with favorable classroom experiences. Paper presented at the Annual Forum of the Association for Institutional Research, Minneapolis, MN.

Wales, C.E. \& Nardi, A. (1982). Teaching decision-making with guided design. Paper presented at the meeting of the Center for Faculty Evaluation and Development, Kansas State University, Manhattan, KS.

Whitman, N. A. (1988). Peer teaching: To teach is to learn twice. (ERIC Document Reproduction Service No. ED 301 016).

The Wingspread Group. (1993). An American imperative: Higher expectations for higher education. Milwaukee, WI: The Johnson Foundation, Inc.

Zoller, U. (1999). Scaling-up of higher-order cognitive skills-oriented college chemistry teaching: An action-oriented model. Journal of Research in Science Teaching, 36(5), 583-596. 


\section{Appendix A}

Faculty Inventory of the Seven Principles for Good Practice in Undergraduate Education The following pages include Chickering and Gamson's unedited Faculty

Inventory as it was presented to survey participants in Survey Monkey. 
There are seven principles of good practice in undergraduate education recognized by Chickering and Gamson. Please select one response for each statement of the survey.

1. Principle 1: Good Practice Encourages Student-Faculty Contact

\begin{tabular}{|c|c|c|c|c|c|}
\hline & Very Often & Often & Occasionally & Rarely & Never \\
\hline $\begin{array}{l}\text { a. I advise my } \\
\text { students about } \\
\text { career opportunities } \\
\text { in their major field. }\end{array}$ & Very Often & Often & Occasionally & Rarely & Never \\
\hline $\begin{array}{l}\text { b. Students drop by } \\
\text { my office just to } \\
\text { visit. }\end{array}$ & Very Often & Often & Occasionally & C Rarely & Never \\
\hline $\begin{array}{l}\text { c. I share my past } \\
\text { experience, } \\
\text { attitudes, and } \\
\text { values with } \\
\text { students. }\end{array}$ & Very Often & Often & Occasionally & Rarely & Never \\
\hline $\begin{array}{l}\text { d. I attend events } \\
\text { sponsored by } \\
\text { student groups. }\end{array}$ & Very Often & Often & Occasionally & Rarely & Never \\
\hline $\begin{array}{l}\text { e. I work with } \\
\text { student affairs staff } \\
\text { on issues related to } \\
\text { student } \\
\text { extracurricular life } \\
\text { and life outside of } \\
\text { school. }\end{array}$ & Very Often & Often & Occasionally & Rarely & Never \\
\hline $\begin{array}{l}\text { f. I know my } \\
\text { students by name by } \\
\text { the end of the first } \\
\text { two weeks of the } \\
\text { term. }\end{array}$ & Very Often & Often & Occasionally & Rarely & Never \\
\hline
\end{tabular}




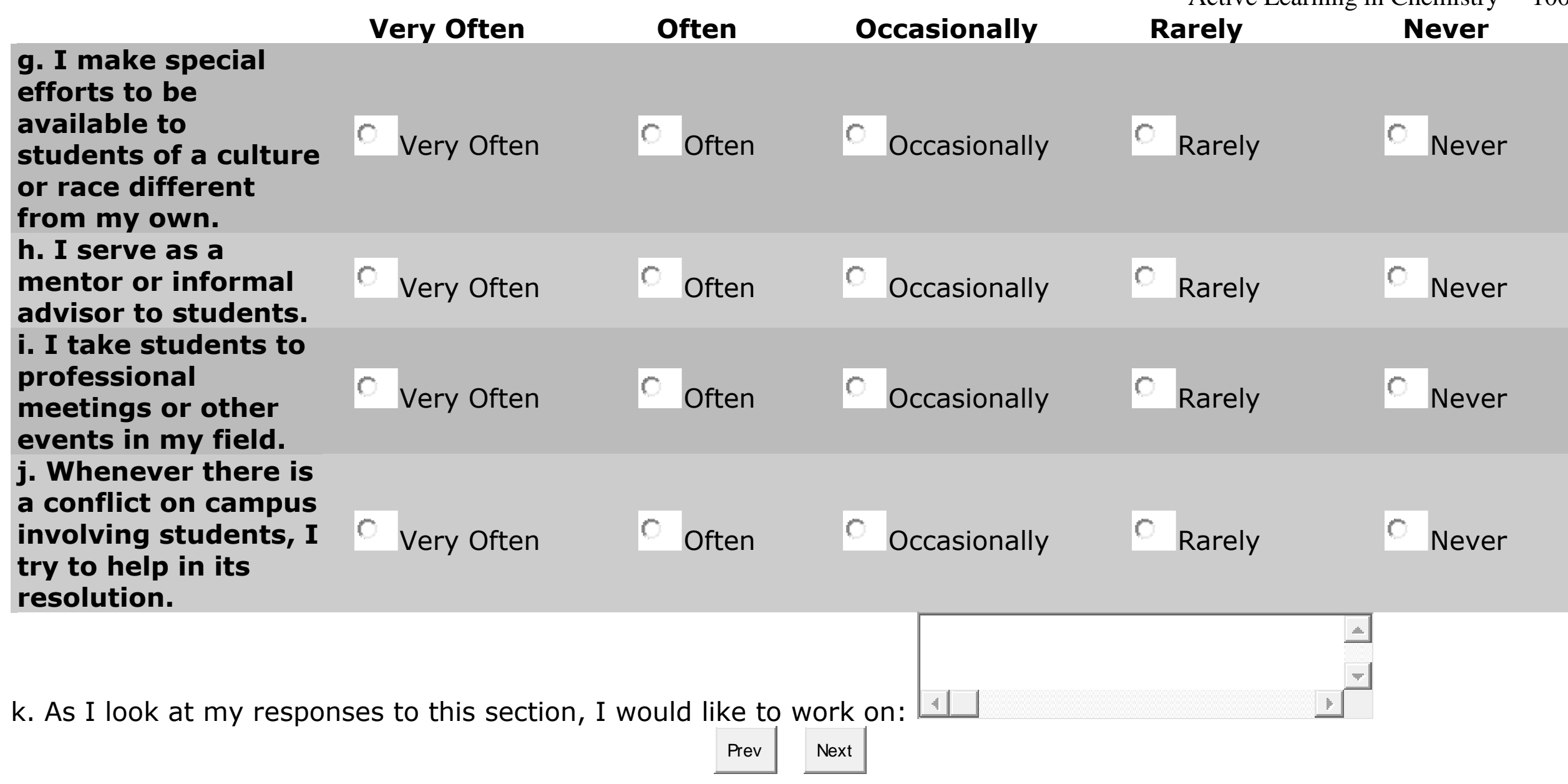


1. Principle 2: Good Practice Encourages Cooperation Among Students

\begin{tabular}{|c|c|c|c|c|c|}
\hline & Very Often & Often & Occasionally & Rarely & Never \\
\hline $\begin{array}{l}\text { a. I ask students to } \\
\text { tell each other about } \\
\text { their interests and } \\
\text { backgrounds. }\end{array}$ & $C$ Very Often & Often & Occasionally & Rarely & Never \\
\hline $\begin{array}{l}\text { b. I encourage my } \\
\text { students to prepare } \\
\text { together for classes } \\
\text { or exams. }\end{array}$ & Very Often & Often & Occasionally & Rarely & Never \\
\hline $\begin{array}{l}\text { c. I encourage } \\
\text { students to do } \\
\text { projects together. }\end{array}$ & Very Often & Often & Occasionally & Rarely & Never \\
\hline $\begin{array}{l}\text { d. I ask my students } \\
\text { to evaluate each } \\
\text { other's work. }\end{array}$ & Very Often & Often & Occasionally & Rarely & Never \\
\hline $\begin{array}{l}\text { e. I ask my students } \\
\text { to explain difficult } \\
\text { ideas to each other. }\end{array}$ & Very Often & Often & Occasionally & Rarely & Never \\
\hline $\begin{array}{l}\text { f. I encourage my } \\
\text { students to praise } \\
\text { each other for their } \\
\text { accomplishments. }\end{array}$ & Very Often & Often & Occasionally & Rarely & Never \\
\hline $\begin{array}{l}\text { g. I ask my students } \\
\text { to discuss key } \\
\text { concepts with other } \\
\text { students whose } \\
\text { backgrounds and } \\
\text { viewpoints are } \\
\text { different from their } \\
\text { own. }\end{array}$ & $C$ Very Often & Often & Occasionally & $\mathrm{C}$ Rarely & Never \\
\hline $\begin{array}{l}\text { h. I create "learning } \\
\text { communities," study } \\
\text { groups, or project }\end{array}$ & $C$ Very Often & Often & Occasionally & Rarely & Never \\
\hline
\end{tabular}




\begin{tabular}{|c|c|c|c|c|c|}
\hline \multirow{2}{*}{\multicolumn{2}{|c|}{ Very Often }} & \multirow[b]{2}{*}{ Often } & \multirow[b]{2}{*}{ Occasionally } & \multicolumn{2}{|c|}{ in Chemistry } \\
\hline & & & & Rarely & Never \\
\hline \multicolumn{6}{|c|}{$\begin{array}{l}\text { teams within my } \\
\text { courses. }\end{array}$} \\
\hline $\begin{array}{l}\text { i. I encourage } \\
\text { students to join at } \\
\text { least one campus } \\
\text { organization. }\end{array}$ & Very Often & Often & Occasionally & Rarely & Never \\
\hline $\begin{array}{l}\text { j. I distribute } \\
\text { performance criteria } \\
\text { to students so that } \\
\text { each person's grade } \\
\text { is independent of } \\
\text { those achieved by } \\
\text { others. }\end{array}$ & Very Often & Often & Occasionally & C Rarely & Never \\
\hline k. As I loo & & & $\mathrm{n}: 41$ & & \\
\hline & & Prev & ext & & \\
\hline
\end{tabular}


1. Principle 3: Good Practice Encourages Active Learning

\begin{tabular}{|c|c|c|c|c|c|}
\hline & Very Often & Often & Occasionally & Rarely & Never \\
\hline $\begin{array}{l}\text { a. I ask my students } \\
\text { to present their } \\
\text { work to the class. }\end{array}$ & Very Often & Often & Occasionally & Rarely & Never \\
\hline $\begin{array}{l}\text { b. I ask my students } \\
\text { to summarize } \\
\text { similarities and } \\
\text { differences among } \\
\text { different theorists, } \\
\text { research findings, or } \\
\text { artistic works. }\end{array}$ & Very Often & Often & Occasionally & Rarely & C Never \\
\hline $\begin{array}{l}\text { c. I ask my students } \\
\text { to relate outside } \\
\text { events or activities } \\
\text { to the subjects } \\
\text { covered in my } \\
\text { courses. }\end{array}$ & Very Often & Often & Occasionally & Rarely & Never \\
\hline $\begin{array}{l}\text { d. I ask my students } \\
\text { to undertake } \\
\text { research or } \\
\text { independent study. }\end{array}$ & Very Often & Often & Occasionally & Rarely & Never \\
\hline $\begin{array}{l}\text { e. I encourage } \\
\text { students to } \\
\text { challenge my ideas, } \\
\text { the ideas of other } \\
\text { students, or those } \\
\text { presented in } \\
\text { readings or other } \\
\text { course materials. }\end{array}$ & Very Often & Often & Occasionally & Rarely & Never \\
\hline $\begin{array}{l}\text { f. I give my students } \\
\text { concrete, real-life } \\
\text { situations to } \\
\text { analyze. }\end{array}$ & $C$ Very Often & Often & Occasionally & Rarely & Never \\
\hline
\end{tabular}


g. I use simulations, role-playing, or labs

in my classes.

h. I encourage my students to suggest new readings, research projects, field trips, or other course activities.

i. My students and I arrange field trips, volunteer activities, or internships related to the course.

j. I carry out research projects

with my students.

k. As I look at my responses to this section, I would like to work on:

Often

Occasionally

Often

Occasionally Rarely

Never

$\checkmark$ Very Often $O$ Often $O$ Occasionally $O$ Rarely

Very Often

Often

Occasionally

C Rarely

Never

(- Very Often
Often
Occasionally $\quad$ Rarely
Never
Very Often

Often

Occasionally

Rarely

Never$$
\text { Prev Next }
$$

1. Principle 4: Good Practice Gives Prompt Feedback

\begin{tabular}{|c|c|c|c|c|c|}
\hline & Very Often & Often & Occasionally & Rarely & Never \\
\hline $\begin{array}{l}\text { a. I give quizzes and } \\
\text { homework } \\
\text { assignments. }\end{array}$ & Very Often & Often & Occasionally & Rarely & Never \\
\hline $\begin{array}{l}\text { b. I prepare } \\
\text { classroom exercises } \\
\text { and problems which } \\
\text { give students }\end{array}$ & Very Often & Often & Occasionally & Rarely & Never \\
\hline
\end{tabular}


immediate feedback

Very Often

Often

Occasionally

Rarely

Never

on how well they do.

c. I return

examinations and

papers within a

Very Often

Often

Occasionally

Rarely

Never

week.

d. I give students detailed evaluations of their work early

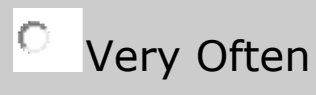

Often

Occasionally

Rarely

Never

in the term.

e. I ask my students

to schedule

conferences with me

to discuss their

Very Often

Often

Occasionally

Rarely

Never

progress.

f. I give my students written comments on their strengths and weaknesses on exams and papers. g. I give my

i. I discuss the students a pre-test at the beginning of each course.

h. I ask students to keep logs or records of their progress. results of the final examination with my students at the end of the semester. j. I call or write a

note to students
Very Often
O Often
Occasionally
Rarely
Never

Very Often

Often

Occasionally

C Rarely

Never

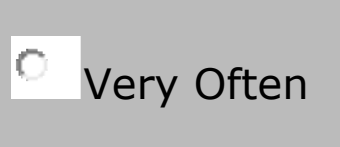

Often

Occasionally

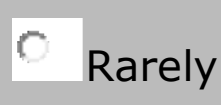

Never
Often

Occasionally

Rarely Never 
who miss classes.

Very Often

Often

Occasionally

Rarely

Never

k. As I look at my responses to this section, I would like to work on:

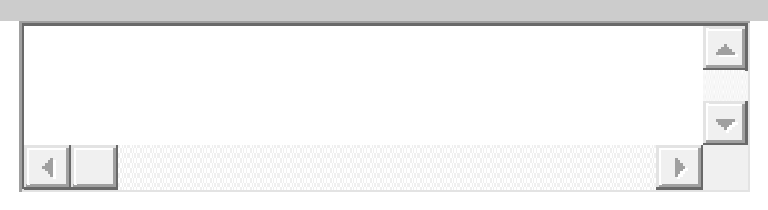

1. Principle 5: Good Practice Emphasizes Time on Task

\begin{tabular}{|c|c|c|c|c|c|}
\hline & Very Often & Often & Occasionally & Rarely & Never \\
\hline $\begin{array}{l}\text { a. I expect my } \\
\text { students to } \\
\text { complete their } \\
\text { assignments } \\
\text { promptly. }\end{array}$ & Very Often & Often & Occasionally & C Rarely & Never \\
\hline $\begin{array}{l}\text { b. I clearly } \\
\text { communicate to my } \\
\text { students the } \\
\text { minimum amount of } \\
\text { time they should } \\
\text { spend preparing for } \\
\text { classes. }\end{array}$ & Very Often & Often & Occasionally & C Rarely & Never \\
\hline $\begin{array}{l}\text { c. I make clear to } \\
\text { my students the } \\
\text { amount of time that } \\
\text { is required to } \\
\text { understand complex } \\
\text { material. }\end{array}$ & Very Often & Often & Occasionally & Rarely & Never \\
\hline $\begin{array}{l}\text { d. I help students } \\
\text { set challenging } \\
\text { goals for their own } \\
\text { learning. }\end{array}$ & $\checkmark$ Very Often & Often & Occasionally & Rarely & Never \\
\hline $\begin{array}{l}\text { e. When oral reports } \\
\text { or class } \\
\text { presentations are } \\
\text { called for I }\end{array}$ & $C$ Very Often & Often & Occasionally & Rarely & Never \\
\hline
\end{tabular}




\begin{tabular}{|c|c|c|c|c|c|}
\hline \multirow{2}{*}{$\begin{array}{l}\text { encourage students } \\
\text { to rehearse in } \\
\text { advance. }\end{array}$} & Very Often & Often & Occasionally & Rarely & \multirow{2}{*}{ Never } \\
\hline & & & & & \\
\hline $\begin{array}{l}\text { f. I underscore the } \\
\text { importance of } \\
\text { regular work, steady } \\
\text { application, sound } \\
\text { self-pacing, and } \\
\text { scheduling. }\end{array}$ & Very Often & Often & Occasionally & Rarely & Never \\
\hline $\begin{array}{l}\text { g. I explain to my } \\
\text { students the } \\
\text { consequences of } \\
\text { non-attendance. }\end{array}$ & Very Often & Often & Occasionally & Rarely & Never \\
\hline $\begin{array}{l}\text { h. I make it clear } \\
\text { that full-time study } \\
\text { is a full-time job } \\
\text { that requires forty } \\
\text { or more hours a } \\
\text { week. }\end{array}$ & $\checkmark$ Very Often & Often & Occasionally & Rarely & Never \\
\hline $\begin{array}{l}\text { i. I meet with } \\
\text { students who fall } \\
\text { behind to discuss } \\
\text { their study habits, } \\
\text { schedules, and other } \\
\text { commitments. }\end{array}$ & Very Often & Often & Occasionally & Rarely & Never \\
\hline $\begin{array}{l}\text { j. If students miss } \\
\text { my classes, I } \\
\text { require them to } \\
\text { make up lost work. }\end{array}$ & Very Often & O Often & Occasionally & Rarely & Never \\
\hline k. As I look at & es t & vould & on: 4 & & \\
\hline
\end{tabular}


1. Principle 6: Good Practice Communicates High Expectations

\begin{tabular}{|c|c|c|c|c|c|}
\hline & Very Often & Often & Occasionally & Rarely & Never \\
\hline $\begin{array}{l}\text { a. I tell students } \\
\text { that I expect them } \\
\text { to work hard in my } \\
\text { classes. }\end{array}$ & Very Often & Often & Occasionally & Rarely & Never \\
\hline $\begin{array}{l}\text { b. I emphasize the } \\
\text { importance of } \\
\text { holding high } \\
\text { standards for } \\
\text { academic } \\
\text { achievement. }\end{array}$ & Very Often & Often & Occasionally & Rarely & Never \\
\hline $\begin{array}{l}\text { c. I make clear my } \\
\text { expectations orally } \\
\text { and in writing at the } \\
\text { beginning of each } \\
\text { course. }\end{array}$ & Very Often & Often & Occasionally & Rarely & Never \\
\hline $\begin{array}{l}\text { d. I help students } \\
\text { set challenging } \\
\text { goals for their own } \\
\text { learning. }\end{array}$ & Very Often & Often & Occasionally & Rarely & Never \\
\hline $\begin{array}{l}\text { e. I explain to } \\
\text { students what will } \\
\text { happen if they do } \\
\text { not complete their } \\
\text { work on time. }\end{array}$ & Very Often & Often & Occasionally & Rarely & Never \\
\hline $\begin{array}{l}\text { f. I suggest extra } \\
\text { reading or writing } \\
\text { tasks. }\end{array}$ & Very Often & Often & Occasionally & Rarely & Never \\
\hline $\begin{array}{l}\text { g. I encourage } \\
\text { students to write a } \\
\text { lot. }\end{array}$ & Very Often & Often & Occasionally & Rarely & Never \\
\hline $\begin{array}{l}\text { h. I publicly call } \\
\text { attention to }\end{array}$ & Very Often & Often & Occasionally & Rarely & Never \\
\hline
\end{tabular}


excellent

Very Often

Often

Occasionally

Rarely

Never

performance by my

students.

i. I revise my courses.

Very Often

Often

Occasionally

Rarely

Never

j. I periodically

discuss how well we

are doing during the

course of the

Very Often $\quad$ Often

Occasionally

Rarely

Never

semester.

k. As I look at my responses to this section, I would like to work on:

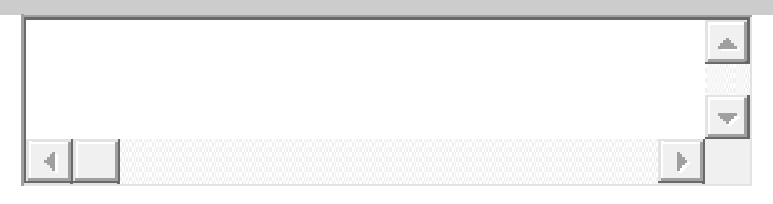

$$
\text { Prev Next }
$$

Principle 7: Good Practice Respects Diverse Talents and Ways of Learning

\begin{tabular}{|c|c|c|c|c|c|}
\hline & Very Often & Often & Occasionally & Rarely & Never \\
\hline $\begin{array}{l}\text { a. I encourage } \\
\text { students to speak } \\
\text { up when they don't } \\
\text { understand. }\end{array}$ & Very Often & Often & Occasionally & Rarely & Never \\
\hline $\begin{array}{l}\text { b. I discourage } \\
\text { stride remarks, } \\
\text { sarcasm, kidding, } \\
\text { and other class } \\
\text { behaviors that may } \\
\text { embarrass students. }\end{array}$ & Very Often & Often & Occasionally & Rarely & Never \\
\hline $\begin{array}{l}\text { C. I use diverse } \\
\text { teaching activities } \\
\text { to address a broad } \\
\text { spectrum of } \\
\text { students. }\end{array}$ & Very Often & Often & Occasionally & Rarely & Never \\
\hline
\end{tabular}


d. I select reading and design activities related to the background of $\mathrm{my}$ students.

e. I provide extra material or exercises for students who lack essential

background

knowledge or skills.

f. I integrate new knowledge about women and other under-represented populations in $\mathrm{my}$ courses. g. I make explicit provisions for students who wish to carry out independent studies within my own course or as separate courses.

h. I have developed mastery learning, learning contracts, or computer assisted learning alternatives for $\mathrm{my}$ courses.

k

Very Often Often

Occasionally Rarely

Never

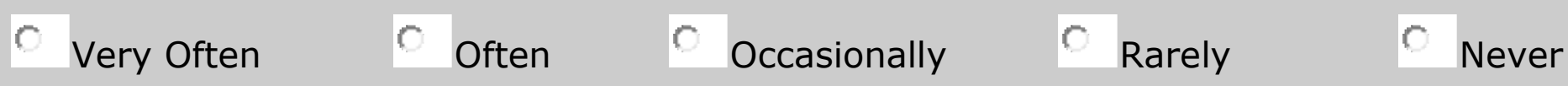
ever

\section{Very Often}

Often

Occasionally

Rarely

Never 
i. I encourage my students to design their own majors when their interests warrant doing so. j. I try to find out about my students' learning styles,

interests, or backgrounds at the beginning of each course.

k. As I look at my responses to this section, I would like to work on:

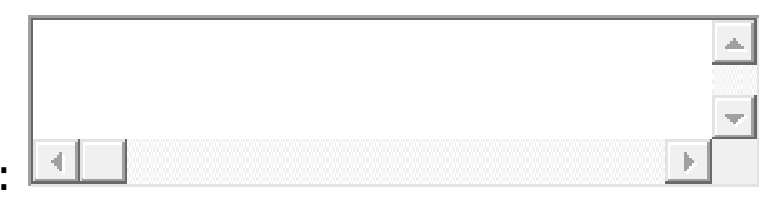
Very Often
Often
Occasionally
Rarely
Never

\section{Never}

Very Often

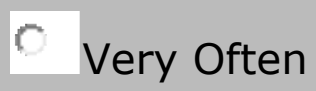

Often

Occasionally

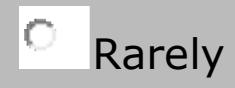

Never

Prev Next 


\section{Appendix B}

\section{Cover Letter to Participants}

\section{Dear Chemistry Instructor,}

I am writing to ask for your assistance in a research survey intended to explore faculty utilization of specific practices in general chemistry courses offered at community colleges. I am researching this topic as a way of completing my dissertation to earn my doctoral degree in Leadership Studies at West Virginia University. Questions are asked to gauge your experience, education, and comfort level with certain principles of undergraduate education by Arthur Chickering and Zelda Gamson. This survey is being distributed to all full time and part time community college chemistry faculty at regionally accredited institutions.

Your participation in this survey is voluntary. However, answers you provide will help us examine an important area of higher education. As more and more students elect community college as the first steps to higher education, a thorough examination of general chemistry and eventually general science courses is important. The answers you give will be kept confidential and your identity will be protected. If you choose to participate in this survey, you do not need to answer every question. We hope that the results of this survey will benefit chemistry instructors by improving and enhancing chemistry teaching. Summary results of this survey may be used in published research in the area of chemical education. Results will be released only in summary form in which no individual survey respondent's answers can be identified.

It is not anticipated that this survey or study will present any significant risks to you. If completing this survey makes you uncomfortable, you can withdraw from the survey at any time.

To participate, please follow the link and complete the survey questions. All information gathered will be kept strictly confidential. This study was approved by the West Virginia University Institutional Review Board for the Protection of Human Subjects (IRB) and was granted exemption. IRB acknowledgement for this study is on file. If you have any questions about this survey or your rights as a research participant, please call Ms. Jennifer Bishoff at 240321-6744.

Thank you for helping me with this important survey.

Sincerely,

Jennifer Bishoff

Graduate Student, Leadership Studies 


\section{Appendix C}

Demographics Questionnaire

1. What is your gender?
a. Male
b. Female

2. Please indicate your employment status.

a. Full-time (teach 12 credits or more at the same institution)

b. Full-time (teach 12 credits or more across different institutions)

c. Part-time (teach less than 12 credits in the Spring 2010 semester)

3. What is your typical chemistry class size?
a. 1 to 20
b. 21 to 40
c. 41 or more

4. How many years have you taught higher education (college or university)?
a. 0 (beginning first year)
b. 1 to 5
c. 6 to 10
d. 11 to 15
e. 16 to 20
f. 21 or more

5. How many years have you taught at this two-year institution?

6. What is the highest degree you have completed?
a. Bachelor's
b. Master's
c. Doctorate
d. Other

7. What was your major?
a. Education
b. Science
c. Other

8. If you selected Other, what was your major?

9. How many credits does the majority of your student population enroll in during a typical semester?

a. Full-time (12 credits or more)

b. Part-time (less than 12 credits)

10. What regional accreditation does your community college hold?

a. The Middle States Association of Colleges and Schools

b. The New England Association of Schools and Colleges

c. The North Central Association of Colleges and Schools

a. The Southern Association of Colleges and Schools 